\title{
Transporte aéreo y pandemia de la COVID-19: ¿Hacia un cambio de trayectoria en la red aeroportuaria española?
}

\author{
Air transportation and the COVID-19 pandemic: Towards a change \\ of the path in the spanish airport network? \\ Roberto Díez-Pisonero \\ rdpisonero@ghis.ucm.es @ 0000-0002-7817-628X
}

Cándida Gago-García

cgago@ucm.es@0000-0003-2315-7943

Departamento de Geografía, Facultad de Geografía e Historia. Universidad Complutense de Madrid. C/ Profesor Aranguren s/n. Ciudad Universitaria. 28040 Madrid, España

\section{INFO ARTÍCULO}

\section{Recibido: $13 / 12 / 2021$}

Revisado: 13/01/2022

Aceptado: 19/01/2022

\section{PALABRAS CLAVE}

Transporte aéreo

COVID-19

Red aeroportuaria

Conectividad

España

\section{KEYWORDS}

Air transportation

COVID-19

Airports

Air connectivity

Spain

\begin{abstract}
RESUMEN
La COVID-19 ha supuesto un profundo shock en la economía global y en particular en la industria de la aviación, al ser esta damnificada de medidas restrictivas para frenar la propagación del virus. En este trabajo además de presentar, como contexto, el impacto de la COVID-19 a escala global en el sector comercial de la aviación, se realiza un análisis de la conectividad aérea de los aeropuertos españoles para comprender los cambios acaecidos. Para el estudio, de carácter diacrónico (1970-2020), se emplea un coeficiente de conectividad topológica, cartografía y otras medidas (análisis de frecuencias y volumen de viajeros). La pandemia está suponiendo un punto de inflexión en la historia aeronáutica que obliga a una adaptación constante en España y en el resto del mundo, tanto en términos comerciales como en materia de seguridad sanitaria.
\end{abstract}




\section{INTRODUCCIÓN}

El trabajo presenta un estudio de la evolución de la movilidad y la conectividad del transporte aéreo en España (doméstico e internacional) después de la primera ola de la pandemia por COVID-19 (primavera de 2020), momento en que, a partir de su declaración por parte de la OMS (Organización Mundial de la Salud), el Gobierno de España declaró el estado de alarma y con ello el confinamiento de la población. Este hecho no fue único, sino que se produjo generalizadamente en casi todos los países del mundo (salvo escasas excepciones), para evitar la propagación de la enfermedad. Pese a todas las restricciones la contención del virus no ha sido posible, siendo el transporte aéreo uno de los vectores fundamentales de su propagación (Sun et al., 2021a), aun cuando se dispuso de numerosas advertencias sobre la importancia de las restricciones en la movilidad en este medio de transporte (Ribeiro et al., 2020).

Todo lo ocurrido debe remitirse al hecho de que la movilidad es una de las características más relevantes de las sociedades contemporáneas. Esta desempeña un rol protagonista en el proceso de globalización, ya que las conexiones se acometen con tal velocidad que permiten la reducción de las distancias y el acercamiento de los territorios (Córdoba et al., 2007). En ello han contribuido ostensiblemente los modernos sistemas de transporte y, muy especialmente la aviación, sector estratégico que tiene un protagonismo decisivo en la actual sociedad globalizada (Graham, 2005).

El avión, elemento y vehículo de la actual civilización técnica, ha posibilitado la percepción de un espacio diferente al que otros medios de transporte superficial pueden ofrecer al permitir comparecer físicamente en un lugar en tiempos reducidos y a escalas muy diferentes (Córdoba et al., 2007). Los estudios sobre los impactos territoriales del transporte aéreo insisten en que a diferencia de las infraestructuras marítima o terrestre, el avión no necesita un contacto físico con la superficie de forma continuada por lo que los flujos y relaciones se desarrollan de manera más flexible y, por consiguiente, menos restrictiva (Cano, 1980), potenciando notoriamente la movilidad, la accesibilidad a lugares enclavados o aislados, los flujos y el intercambio, al superar las restricciones ocasionadas por las condiciones orográficas. Por tanto, puede adquirir un papel decisivo como instrumento de cohesión territorial (Hernández Luis, 2010).

Ello ha contribuido a una nueva percepción en que el ser humano se relaciona con el espacio, expresada en términos de "convergencia espacio-temporal" (Janelle, 1969), "plasticidad" (Relp, 1976; Forer, 1978) o "compresión espacio-temporal" (Harvey, 1983), entre otras denominaciones. Las distancias euclidianas son sustituidas por otras de carácter funcional, cuya percepción viene definida en términos de frecuencias, tiempos de desplazamiento y cantidad de pasajeros y mercancías (Gago, 2003; Díez-Pisonero, 2015). No obstante, ello no constituye un fenómeno generalizado. El paradigma de la movilidad, desarrollado desde las Ciencias Sociales, enfatiza el carácter asimétrico y la espacialidad diferencial que genera la movilidad en general (Larsen et al., 2006) y en particular, el transporte aéreo entre aquellos espacios e individuos intensamente comunicados y los que no lo están. Este paradigma, conocido con el anglicismo "mobility turn", fue propuesto en la década de 1990 por el sociólogo británico John Urry para enfatizar el papel y la importancia histórica y contemporánea de todos los tipos de movilidad (ideas, capitales, turistas, trabajadores, mercancías, servicios, etc.) sobre los individuos y la sociedad. Esta movilidad también puede entenderse en relación con las clases sociales, los ingresos o los flujos diferenciales entre territorios (Urry, 2020).

Según estos planteamientos, las disimilitudes entre lugares tienden a intensificarse, ya que un mundo de flujos hace que se incremente la competitividad, al tiempo que se produce simultáneamente una importante convergencia de los países ricos y nuevas polarizaciones (Cumings, 1999). Estas opiniones sostienen que los procesos de compresión espacio-temporal y de re-escalamiento ligados al transporte aéreo son básicamente elitistas (Stein, 2001), siendo manifestaciones de un desarrollo desigual y de relaciones de poder, dominación y subordinación en un mundo que se encoge, pero no de manera equitativa ni social ni territorialmente (Agnew, 2001; Knowles 2006). Fruto también del capitalismo, estos avances de la conectividad responden a las demandas de los procesos de producción (Cresswell, 2006), reflejando, así, cómo se construyen las cambiantes geografías de la accesibilidad en el tiempo, por ejemplo, en la formación y destrucción de los diferentes patrones de centralidad y perificidad que, inevitablemente, favorecen a algunos grupos y lugares más que a otros. Se trata de un debate abierto, pues incluso en la gestión de la epidemia 
global se observan los efectos diferenciales que imprimen las redes de transporte a los territorios (acceso a recursos, abastecimiento, movilidad, centralidad, accesibilidad, entre otros).

A pesar de que el transporte aéreo ha facilitado visiblemente la compresión del mundo, últimamente se ha puesto de relieve que también, como vector de la globalización, ha contribuido a la propagación de enfermedades, virus y pandemias, como la de la COVID-19. Esta ha supuesto un profundo varapalo en la economía global. Por ejemplo, en 2020 el PIB mundial decreció como media un -3,4\%, e incluso un punto porcentual más en los países de la OECD (-4,7\%), con un aumento de la tasa de desempleo hasta el 7,1\% del total de la fuerza laboral del planeta, frente al 6,5\% de media en el periodo de 2013 a 2019 (OECD, 2021).

La propagación de la enfermedad infecciosa provocada por el virus SRAS-CoV-2 no es un caso aislado, pues se dispone de ejemplos anteriores a la actual pandemia, que advertían de esa posibilidad, por ejemplo con el caso de la pandemia de gripe originada en México (gripe A- H1N1) entre 2009-2010 (Omic \& Van Mieghem, 2010). No obstante, la gravedad de la enfermedad (defunciones y secuelas en los pacientes) ${ }^{1}$ ha desencadenado una reflexión rápida, intensa y prolífica, en los organismos multilaterales (ej. OMS), en los gobiernos, en el mundo académico y de la investigación y también en la opinión pública, sobre los mecanismos por los cuales se ha transmitido tan raudamente por el planeta. Sirva como ejemplo de este interés que un rastreo en el buscador de trabajos académicos Google Scholar realizada con la palabra "COVID-19" ha devuelto a los autores que firman este artículo más de 4.400 .000 resultados (búsqueda realizada el 15 de noviembre de 2021).

En este trabajo se utilizarán indicadores de conectividad de la red de transporte aéreo, lo que permitirá, en primer lugar, conocer el impacto de la pandemia en el sector de la aviación comercial a escala global, a raíz de datos y estadísticas oficiales de los principales organismos de la industria aeronáutica y, en segundo lugar, realizar un análisis de la conectividad aérea de los aeropuertos españoles. Esto último posibilitará comprender y visualizar los cambios acaecidos en la red aeroportuaria española, mostrando y evaluando el impacto de la pandemia (2019-2020). La lógica que hay detrás de este análisis es detectar qué trayectorias, en un periodo amplio (1970-2015), han sido truncadas por la pandemia y también qué conexiones aéreas han resistido la crisis, indicador de la robustez de los vínculos territoriales entre pares de ciudades conectadas.

Para ello, se analizará diacrónicamente el grado de vertebración nacional entre los sistemas urbanos (conectividad nacional) y la evolución de la participación de los aeropuertos españoles en el escenario internacional (conectividad externa) en los dos tramos temporales identificados, a través del estudio de la conectividad, fundamentalmente por medio de un coeficiente de conectividad topológica. El trabajo se cierra con las conclusiones de la investigación.

\section{LA COVID-19 Y EL TRANSPORTE AÉREO. ESTADO DE LA CUESTIÓN}

La magnitud del crecimiento del sistema de transporte aéreo ( $n^{\circ}$ de operaciones y volumen de pasajeros transportados) desde la década de 1970 es visible a cualquier escala de análisis. Deteniéndose en la escala mundo (figura 1), se observa una evolución positiva y constante durante las últimas décadas en el tráfico de pasajeros, salvo momentos de retroceso coyuntural, ligado a crisis económicas o bélicas que ocasionaban un encarecimiento del combustible y/o el temor a los desplazamientos (Oprea, 2010; Dobruszkes \& Van Hamme, 2011; Chi \& Baek, 2013). Esto es ejemplo de las indiscutibles relaciones entre transporte aéreo y actividad económica (Ishutkina \& Hansman, 2008) y también, de forma muy acusada, con la actividad turística (Sorupia, 2005).

Hasta 2020 el principal evento que hizo tambalear el sector aéreo en la escala global fueron los atentados terroristas del 11S en Nueva York (figura 1). Ello impactó sobre las frecuencias y el volumen de pasajeros de forma muy rápida (Inglada \& Rey, 2004; Ito \& Lee, 2005). No obstante, la magnitud del shock en el sector de

1 En la fecha de revisión de este artículo, 11-12-2021, en el mundo se habían contagiado 270 millones de personas con el virus de la COVID-19. Esta infección había causado hasta ese momento 5.300.000 defunciones. Fuente: COVID-19 Dashboard by the Center for Systems Science and Engineering (CSSE) at Johns Hopkins University (JHU). Obtenido de: https://coronavirus.jhu.edu/map.html 
la actual crisis sanitaria, motivada por la pandemia de la COVID-19, ha llevado a muchos expertos a calificarla como la peor de toda la historia de la aviación comercial: si la predicción del tráfico mundial para 2020, antes de la declaración de la pandemia por la OMS en marzo de ese mismo año, era de 9.400 millones de pasajeros, la cifra se ha visto mermada hasta los 3.800 millones $\left(\mathrm{OACI}^{2}, 2020\right)$. Esta crisis es incluso peor que el escenario generado tras los citados ataques terroristas del 11-S, cuando el sector aéreo tardó cerca de una década en recuperarse por completo (Wyman, 2020).

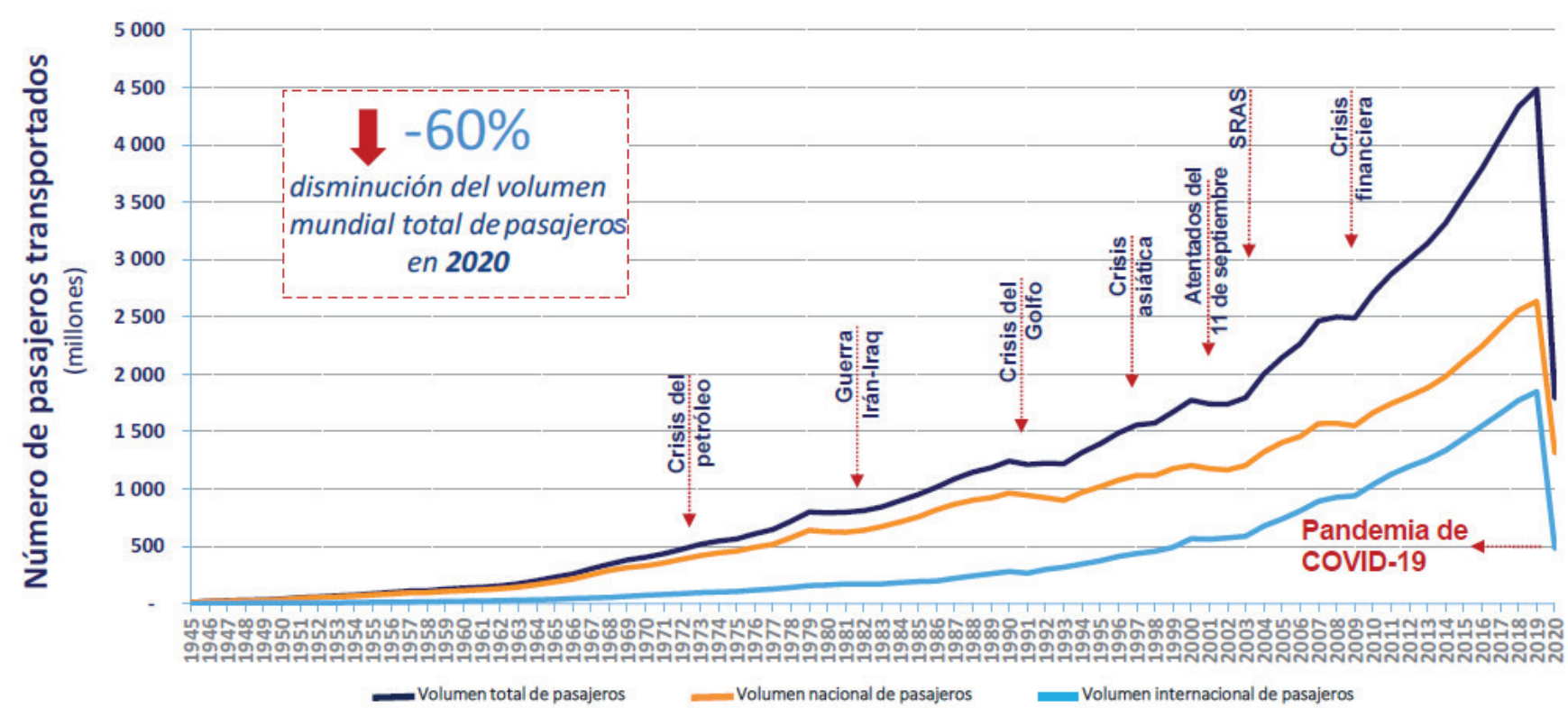

Figura 1. Impacto de la pandemia de la COVID-19 en la evolución del número de pasajeros aéreos. Fuente: OACI (2021c).

El brote del coronavirus en Wuhan (China) y su rápida expansión al resto del mundo obligó a muchos países a poner en marcha medidas restrictivas y de contención para frenar la propagación del virus, lo que ha asestado un golpe muy violento a toda la industria aérea. En pocos días, casi todos los vuelos fueron cancelados, los aeropuertos cerrados, la flota mundial en tierra y miles de empleados despedidos, tal como se demuestra en las siguientes líneas y en la figura 1. El confinamiento y el cierre de las fronteras decretados casi simultáneamente por los gobiernos de todo el mundo derivó en una reducción de más del 85\% del transporte aéreo mundial (IATA, 2020), con repercusiones en todos los sectores vinculados a la actividad. Según la OACI (2020), este impacto se constata así:

- En el tráfico aéreo de pasajeros: reducción general de pasajeros (tanto internacionales como nacionales) que oscila entre el 59\% y el 60\% en 2020, en comparación con 2019 (OACI, 2020).

- En la actividad de los aeropuertos: pérdida estimada de aproximadamente el 64,2\% del tráfico de pasajeros y el $65 \%$ (más de 111,8 mil millones de USD) en ingresos aeroportuarios en 2020, en comparación con los negocios habituales (según la ACI). En ello se incluyen las pérdidas económicas en las infraestructuras, por la ausencia de facturación en los slots, en las actividades de despegue y aterrizaje y también por la caída en la demanda de los servicios auxiliares en las zonas comerciales (restaurantes, cafeterías y tiendas de duty free). Por ejemplo, AENA ${ }^{3}$ registró pérdidas de alrededor

2 OACI: acrónimo de Organización de Aviación Civil Internacional. Organismo dependiente de Naciones Unidas, creado en 1944. Constituye un foro para los Estados en relación con el funcionamiento de la aviación civil, desarrollando políticas y normas, realizando auditorías de cumplimiento, estudios y análisis. También brinda asistencia técnica y coordina la capacidad técnica y operativa de la aviación comercial en la escala mundo. Sus siglas en inglés son ICAO (International Civil Aviation Organization).

3 AENA: Aeropuertos Españoles y Navegación Aérea. Empresa pública encargada de la gestión de la red de aeropuertos y helipuertos de interés general del Estado de España. 
de 346,4 millones de euros durante el primer semestre del año 2021 (el doble de los 170,7 millones en "números rojos" que reportó durante el mismo periodo del año anterior) por el desplome de sus ingresos, provocado con las restricciones a la movilidad por la pandemia (Muñoz, 2021).

- En la economía de las aerolíneas: disminución del 66,3\% en los ingresos por pasajeros por kilómetros (RPK, tanto internacionales como nacionales) en 2020, en comparación con 2019 (según la IATA).

- En la actividad turística en general: disminución en los ingresos por turismo internacional de entre 910 y 1.170 mil millones de USD en 2020, en comparación con los 1,5 miles de millones de USD generados en 2019, con el 100\% de los destinos en todo el mundo con restricciones de viaje (según la UNWTO).

- En el comercio mundial: caída del volumen del comercio mundial de mercancías en un 9,2\% en 2020, en comparación con 2019 (según la WTO-OMC). Ello se ve también reflejado en el tráfico aéreo de mercancías, principalmente debido a la reducción de los vuelos comerciales, que las transportaban en las bodegas de las aeronaves. Consecuentemente, la capacidad de carga aérea en la "primera pulsión" de la pandemia cayó aproximadamente en un $80 \%$, precisamente cuando a escala global era más necesaria la ayuda de emergencia y las dotaciones de material sanitario. No obstante, el segmento de carga se ha recuperado rápidamente y a finales de 2020 el número de vuelos de carga operados a nivel mundial se había expandido en un 2,74\%, con respecto a 2019 (OACI, 2021 b).

La caída del tráfico aéreo empezó a hacerse evidente a mediados del mes de marzo de 2020, cuando los cierres de fronteras y confinamientos comenzaron a generalizarse en Europa y América. Este impacto se materializó en todos los aeropuertos del mundo, con especial hincapié en algunos de los principales hubs, que experimentaron una paralización en la evolución de los pasajeros aéreos durante los meses más duros del confinamiento (figura 2).

Con el objetivo de minimizar los impactos en el número de pasajeros aéreos, en el empleo y en las economías de todo el mundo, la IATA 4 instó a los gobiernos a coordinarse para levantar las restricciones fronterizas y encontrar alternativas a las medidas de cuarentena. Será a partir de julio de 2020 cuando, paulatinamente, el sector del transporte aéreo empezaría a reanudar su actividad con la reapertura de las fronteras, con un incremento muy rápido sobre todo en los subsistemas domésticos (Sun et al., 2021b); no obstante, todavía a finales del año 2021, el tráfico aéreo seguía siendo relativamente bajo, por debajo de los niveles previos (OACI, 2021a). También es posible encontrar impactos y trayectorias de recuperación del sector diversas debido a estrategias muy heterogéneas en la gestión de las restricciones de la movilidad. Por ejemplo, desde una "perspectiva epidemiológica la estrategia desarrollada en China, basada en prohibiciones extremas de viaje y requisitos de cuarentena, podría considerarse la mejor. Desde la perspectiva económica, de garantía de la movilidad y de viabilidad del sector, el enfoque desarrollado en Estados Unidos, basado en permitir un alto grado de tráfico aéreo nacional a pesar de la creciente presión de la pandemia, es el óptimo; mientras que en Europa se optó por una estrategia intermedia" (Sun et al., 2021b, p. 10). Ello generó también impactos diferenciales en estas tres grandes regiones de conectividad, con un profundo pero muy corto impacto en China y mucho más prolongado y heterogéneo en el caso de los países europeos.

Descendiendo escalarmente, se evidencia que todas las regiones del mundo han experimentado una caída generalizada de los asientos ofrecidos por las compañías, de los pasajeros y de los ingresos operativos brutos de las aerolíneas (figura 3). Como ya se ha señalado, en términos generales, el impacto ha sido mayor en los mercados internacionales que en los domésticos, que fueron el refugio de muchas empresas para mantener un cierto nivel de actividad. Es importante destacar que, en muchos casos, las aerolíneas de bajo coste fueron más resilientes y no empezaron a reducir su oferta de vuelos hasta la primera mitad de marzo, al estar menos expuestas al tráfico internacional y al transcontinental que las aerolíneas de red (que operan una flota amplia y diversa) (Atlas Magazine, 2020).

4 IATA: International Air Transport Association. Asociación comercial de las aerolíneas en el mundo, representando a unas 290 aerolíneas o el $83 \%$ del tráfico aéreo total. Apoya a distintas áreas de la actividad de la aviación y propone políticas para la industria del sector. Fuente IATA, obtenido de: https://www.iata.org/en/about/ 
Roberto Díez-Pisonero \& Cándida Gago-García / REA N. 43 (2022) 159-187
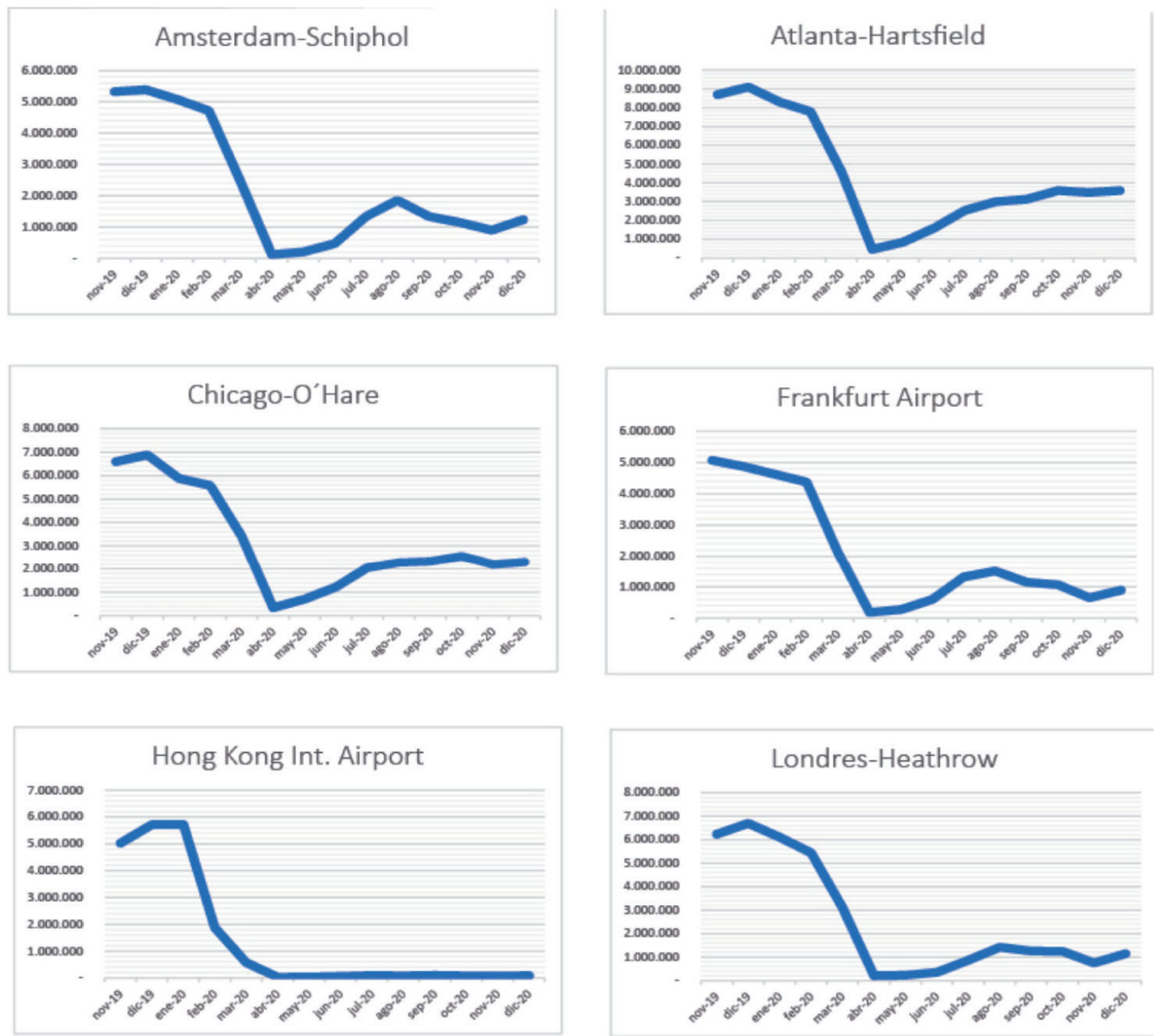

$\overline{164}$
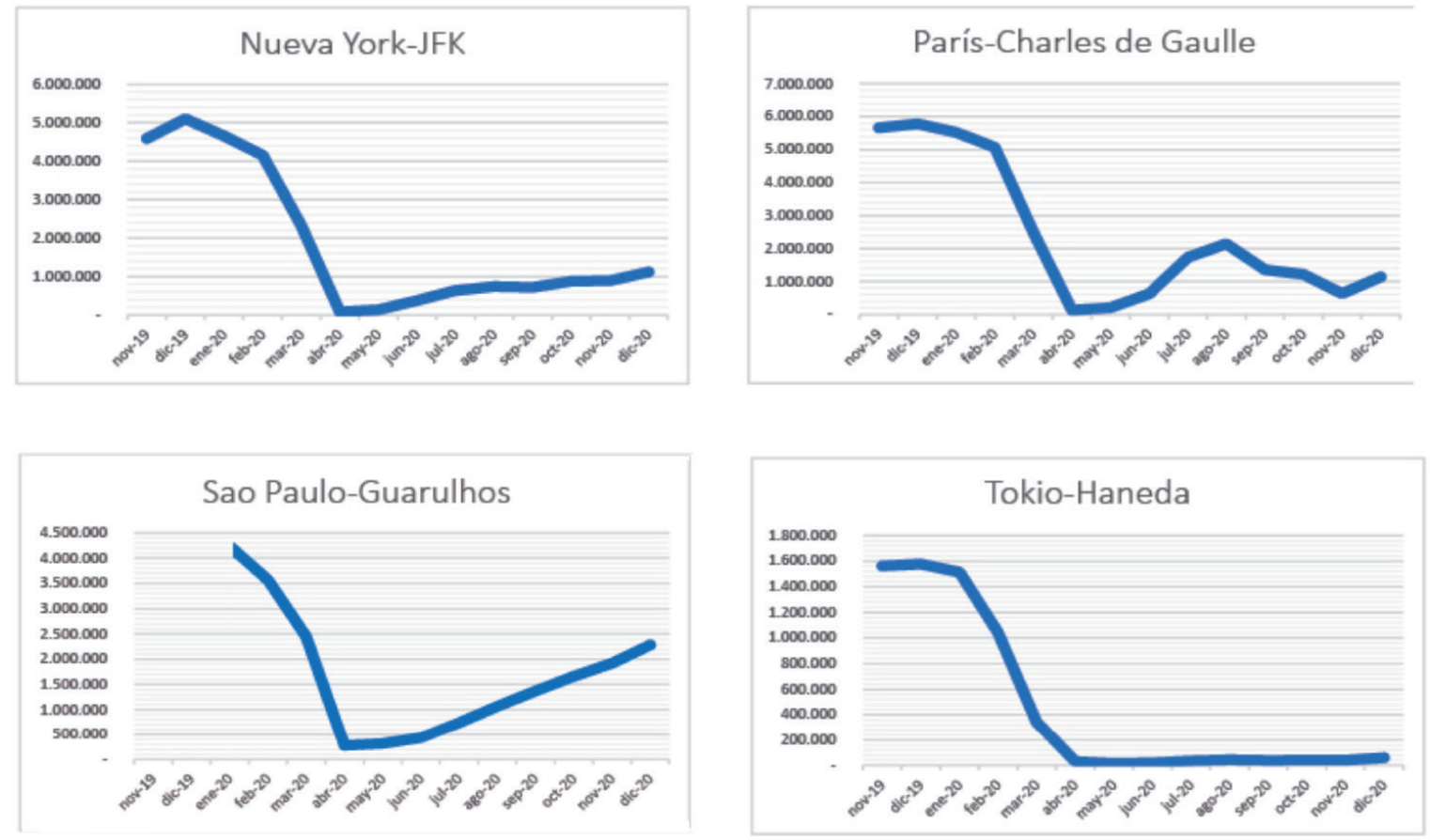

Figura 2. Impacto de la pandemia de la COVID-19 en la evolución del número de pasajeros aéreos (selección de hubs aéreos mundiales; nov/2019-dic/2020). Fuente: Elaboración propia a partir de las páginas web de los respectivos aeropuertos.

(c) Editorial Universidad de Sevilla 2022 | Sevilla, España| CC BY-NC-ND 4.0 | e-ISSN: 2340-2776 | doi: https://dx.doi.org/10.12795/rea.2022.i43.09 


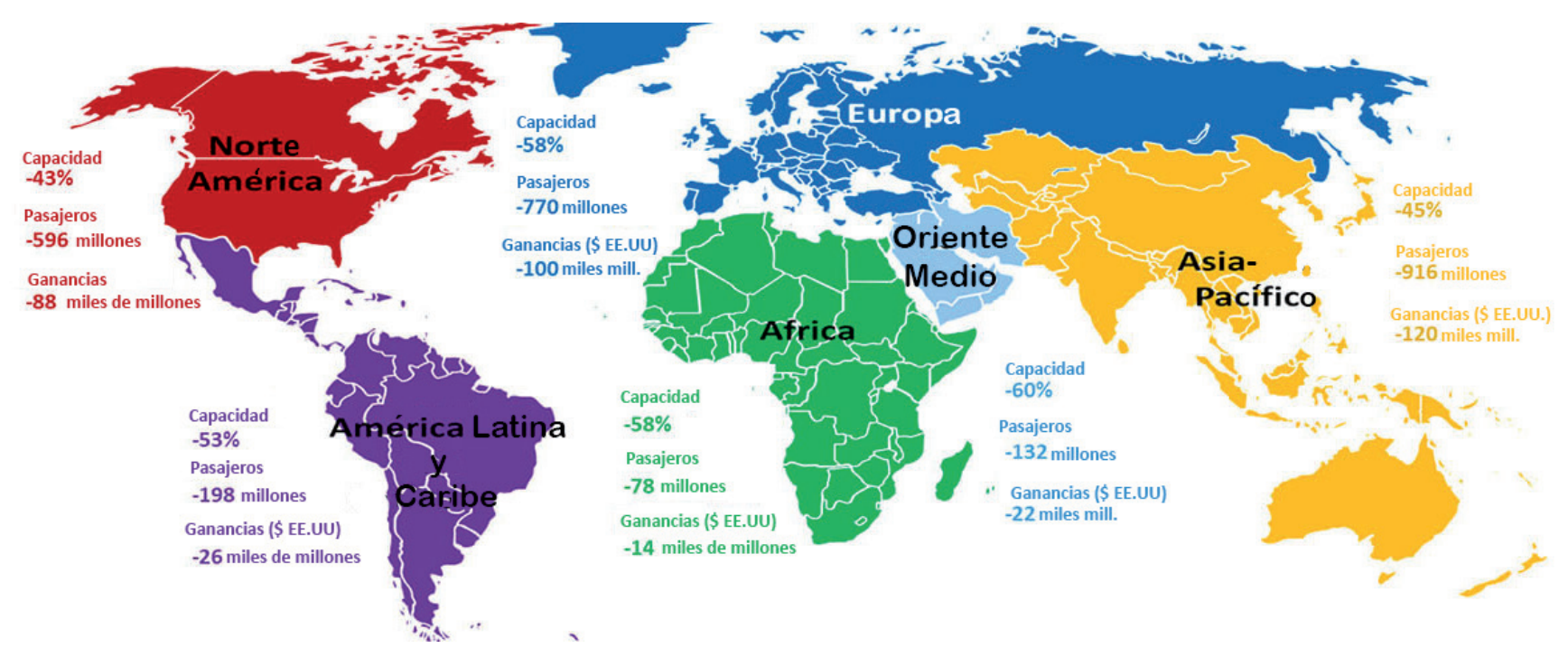

Figura 3. Impacto estimado en el tráfico de pasajeros internacionales e ingresos por grandes regiones mundiales para 2020. Fuente: OACI (2020). Traducción al castellano.

Resulta evidente que la pandemia ha ocasionado una paralización de gran parte de la flota de los operadores a nivel mundial, con el consiguiente cierre de rutas y mercados, que ha supuesto un impacto negativo para los resultados económicos y financieros de todas las compañías aéreas. Aunque algunas de ellas ya se encontraban en una situación desesperada antes del brote de la COVID-19, estas se han visto gravemente afectadas por la crisis sanitaria. Especialmente, durante los meses más duros del confinamiento, se vieron obligadas a tomar medidas drásticas y cancelar numerosas operaciones, reducir las frecuencias de muchas rutas o limitar los aeropuertos de llegada de sus vuelos procedentes del extranjero, todo ello de acuerdo con las restricciones adoptadas. Como resultado, muchas compañías aéreas se declararon en quiebra, como Virgin Australia, Latam, Aeroméxico o Flybe, entre otras. Otras deben su supervivencia únicamente a la intervención de sus respectivos gobiernos estatales a través de rescates económicos, como Alitalia, Air France, KLM-Royal Dutch Airlines o Lufthansa (Atlas Magazine, 2020).

Como se puede observar, la pandemia ha supuesto un profundo varapalo en la economía global, en general, y en la industria de la aviación, en particular. Según los diferentes estudios mensuales que la IATA ha estado publicando en su web durante el transcurso de la pandemia y de acuerdo a las estimaciones, se confirma que el posible impacto de la COVID-19 en la industria aérea será muy elevado, aunque las repercusiones reales dependerán de la duración y la magnitud del brote, de las medidas de contención, del grado de confianza del consumidor en los viajes aéreos, de las condiciones económicas y de la marcha del proceso de vacunación, entre otros factores. Es, por ello, que las autoridades advierten que el regreso a la normalidad no está en la agenda para el futuro inmediato, pues se prevé que la industria no vuelva a los niveles de actividad de 2019 hasta el año 2024 (IATA, 2020).

\section{METODOLOGÍA}

Para evaluar la conectividad aeroportuaria española (doméstica e internacional) y, por consiguiente, analizar el grado de vertebración nacional entre los sistemas urbanos (conectividad doméstica) y la evolución de la participación de muchos de los aeropuertos españoles en el escenario global durante la pandemia (conectividad internacional), se ha realizado un análisis diacrónico, con una "fotografía" de los años 1970, 2015, 2019 y 2020. La lógica es identificar los patrones de evolución de la red (antes de la pandemia, en una trayectoria amplia, 1970-2015) y ver qué dinámicas han sido las más afectadas comparando la situación entre las diferentes fechas. 
Es necesario señalar que la investigación debe ajustarse a la disponibilidad de datos del equipo. El tratamiento estadístico de las diferentes variables (conexiones y frecuencias) se ha llevado a cabo para los años 1970, 2015, 2019 y 2020. Las dos primeras fechas (1970-2015), con 45 años de diferencia, ofrecen un margen de tiempo adecuado para comprender y visualizar las trayectorias acaecidas en la red aeroportuaria española. Estas deben ponerse esencialmente en relación con la restructuración del sector, con especial énfasis en las consecuencias derivadas del proceso de liberalización y en el incremento del turismo internacional (Díez-Pisonero, 2016). La consideración en el análisis del último periodo, años de 2019 a 2020, tiene por objetivo mostrar y evaluar la situación inmediatamente prepandémica y el impacto de la pandemia.

Se han empleado para el análisis datos de conexiones y frecuencias entre pares de ciudades, tanto de tráfico doméstico como internacional, extraídas a partir de las conocidas en el sector como Guías ABC. En 1970, en formato papel "ABC World Airways Guide, October 1970" y, en 2015, 2019 y 2020, en formato digital "Base de datos de Comber International Guides -OAG". Los datos están referidos en todo caso a los meses del final de verano (agosto y septiembre).

Estos se han sometido a un tratamiento estadístico, utilizando para el análisis el cálculo de un coeficiente de conectividad topológica (Córdoba \& Gago, 2010). Para la interpretación también se han utilizado, cuando así la lógica lo recomienda, datos sobre frecuencias aéreas entre pares de ciudades, procedentes de las fuentes anteriormente citadas.

El coeficiente de Conectividad (CC) es una medida topológica que evalúa la conectividad real de un nodo (los arcos que unen ese nodo con otros) en relación con su conectividad potencial (el número total de arcos susceptibles de relacionar el nodo con los demás del sistema, es decir, todos menos él mismo). El significado de esta medida de conectividad, debe ponerse en relación con el vínculo que se establece entre dos ciudades más allá de una frecuencia de vuelo muy alta. Así, para una ciudad escasamente conectada y su hinterland o área de influencia aeroportuaria (el territorio al que sirve), el aumento de las conexiones con otros nodos incrementa la centralidad topológica, favoreciendo el desenclave. Ocurre así, en el transporte aéreo, especialmente en el de carácter doméstico, que muchas veces una línea no resulta especialmente rentable para las compañías comerciales, pero aun así se conserva en relación con criterios de servicio público. En ello juegan un papel fundamental las subvenciones públicas (de carácter estatal o regional, aunque muy limitadas en Europa debido a la desregulación del sector), pero también la limitación de la frecuencia (que puede ser no muy alta, con ello concentrando la demanda en uno o dos días, semanalmente) o la organización operativa interna de los diferentes planes de vuelo de las aeronaves a lo largo de la semana.

La expresión matemática del coeficiente de conectividad se muestra en la figura 4:

$$
\mathrm{CC}_{\mathrm{V}_{\mathrm{i}}}=\frac{\sum_{\mathrm{i}=1}^{\mathrm{N}_{\mathrm{j}}-1} \mathrm{a}_{\mathrm{i}}}{\mathrm{N}_{\mathrm{j}}} \cdot 100 \quad \text { para } \quad \mathbf{a}_{\mathrm{i}}=\left[\begin{array}{l}
1 \text { if } \operatorname{gbranch}\left(\mathrm{V}_{\mathrm{i}}, \mathrm{V}_{\mathrm{j}}\right) \\
0 \text { if } \not \text { bbranch }\left(\mathrm{V}_{\mathrm{i}}, \mathrm{V}_{\mathrm{j}}\right)
\end{array}\right.
$$

donde:

$\mathrm{CC}=$ Coeficiente de Conectividad

$\mathrm{v}_{\mathrm{i}}=$ nodo $i$

$a_{\mathrm{i}}=$ relaciones (arcos) del nodo $i$

$\mathrm{N}_{\mathrm{j}}=$ todos los nodos del sistema

$100=$ multiplicador para obtener datos en tantos por cien

Figura 4. Fórmula del coeficiente de conectividad. Fuente: Córdoba \& Gago (2010).

Para analizar la evolución de la red de transporte aéreo doméstica y siguiendo estas indicaciones, se obtiene el coeficiente de conectividad teórico de cada aeropuerto (considerando todos los aeropuertos de 
la red española). Sin embargo, para obtener unos resultados más exhaustivos conviene establecer unas restricciones para cada una de las infraestructuras aeroportuarias. En concreto, estas limitaciones consisten en:

Por un lado, para la obtención de los resultados se ha decidido descartar una serie de infraestructuras por las siguientes razones:

- En 1970 no se han considerado un total de diez aeropuertos de la red general: Jerez, Vitoria, Badajoz, Murcia (Alcantarilla), Madrid-Cuatro Vientos, Granada, León y Sabadell. Se trata de infraestructuras que registraron un volumen de pasajeros muy reducido y, además, únicamente de tráfico no regular-nacional. Los aeropuertos de Castellón y Lleida no estaban todavía construidos.

- Para el año 2015 se han descartado nueve infraestructuras por diferentes razones: en primer lugar, Huesca-Pirineos, Madrid-Torrejón, Madrid-Cuatro Vientos, Sabadell y Son Bonet (tráfico no comercial), Ciudad Real y Castellón (iniciativa privada), Córdoba y Ceuta (por ausencia o escasez de datos homologables para el análisis, aparte de presentar un escaso volumen de pasajeros).

- Para los años de 2019 y 2020 se han obviado en el análisis: Huesca-Pirineos, Madrid-Torrejón, Madrid-Cuatro Vientos, Sabadell, Son-Bonet, (por escaso volumen de pasajeros), Burgos, Córdoba, León, Lleida, Logroño, Salamanca, Ceuta (por ausencia de datos homologables para el análisis); Ciudad Real y Castellón (iniciativa privada).

Por otro lado, las restricciones en la inclusión de nodos para el caso del análisis de la conectividad doméstica derivan, también, de la distancia o cercanía entre aeropuertos. Como sabemos, el transporte aéreo requiere una distancia mínima para garantizar su efectividad, ya que los aeropuertos también compiten en la atracción de la demanda en un área amplia. Se considera que la distancia de 250 kilómetros es idónea para determinar una baja competencia en la atracción de la demanda entre aeropuertos cercanos (Díez-Pisonero, 2016). De esta manera, además de restar el propio aeropuerto estudiado del número total de nodos, se procederá a excluir a todos aquellos que se encuentren en un radio de acción inferior a esa distancia. Así, se obtiene el coeficiente de conectividad ajustado (CCA), más certero, que permitirá aproximar en mayor medida a la realidad aérea española y, por consiguiente, el valor real del grado de cohesión de la red en su conjunto.

La metodología también incluye el cálculo de coeficientes de conectividad internacional de los aeropuertos españoles (total de conexiones del aeropuerto respecto al total de conexiones internacionales desde España). Se ha recurrido también a las estadísticas sobre el volumen de viajeros domésticos e internacionales. Las fuentes han sido las estadísticas de AENA y del Ministerio de Transportes, Movilidad y Agenda urbana. Por último, el análisis se apoya en cartografía temática sobre conexiones aéreas nacionales y volumen de pasajeros (nacionales e internacionales), para la mejor interpretación de los resultados. También es necesario señalar algunas especificidades temáticas del análisis. Este se refiere al estudio de la aviación comercial de pasajeros. No aborda el tráfico de mercancías y el sector logístico que ya se ha indicado que no sufrió los impactos de manera tan descarnada 5 .

\section{TRAYECTORIA DE LA RED AEROPORTUARIA ESPAÑOLA (1970-2015)}

La primera fase del estudio pretende valorar las dinámicas de largo plazo de la red de transporte aéreo en España. En primer lugar, se puede corroborar cómo en estos 45 años el grado de cohesión del sistema ha evolucionado favorablemente, tanto en el ámbito nacional como internacional. En el primer caso, el grado de cohesión ha pasado del $18,17 \%$ al $24,09 \%$, mientras que para la conexión del sistema internacionalmente los registros han incrementado del 4,98\% al 11,23\% (tabla 1; figuras 5 y 6 ). Es decir, en ambos casos, el número de enlaces aéreos ha aumentado de manera considerable.

5 Durante la pandemia, el papel de la industria de carga aérea ha sido crítico, manteniendo abiertas las cadenas internacionales de suministro. Para muchas aerolíneas, la carga se convirtió en una fuente vital de ingresos cuando los vuelos de pasajeros estaban en tierra. En 2020, la industria de carga aérea generó 129 mil millones de USD, lo que representó aproximadamente un tercio de los ingresos totales de las aerolíneas y un aumento del 10-15\% en comparación con los niveles anteriores a la crisis (IATA, 2021). 
Tabla 1. Grado de cohesión de la red aeroportuaria española (1970-2015).

\begin{tabular}{|c|c|c|c|}
\hline \multicolumn{2}{|c|}{1970} & & 2015 \\
\hline $\begin{array}{c}\text { CC nacional } \\
(\mathrm{N}=31)\end{array}$ & CC internacional $(\mathrm{N}=44)$ & $\begin{array}{c}\text { CC nacional } \\
(\mathrm{N}=39)\end{array}$ & CC internacional $(\mathrm{N}=266)$ \\
\hline $18,17 \%$ & $4,98 \%$ & $24,09 \%$ & $11,23 \%$ \\
\hline
\end{tabular}

Fuente: Resultados de la investigación a partir de las Guías ABC-Comber International Guides -OAG.

Aunque son varios los factores que intervienen en esta evolución positiva, uno de los determinantes ha sido el proceso de liberalización experimentado por el sector de la aviación a finales del siglo pasado. El sector aeronáutico español, previo a dicho proceso, estaba muy regulado y protegido (Antón \& Córdoba, 1999) y el Grupo Iberia ejercía prácticamente de monopolio. Pero, tras los paquetes de medidas liberalizadoras de 1989, 1990 y 1992, inducidos en buena medida por la política de cielos abiertos de la Unión Europea (Gago, 2003), el transporte de pasajeros en España experimentó una gran revolución, con la creación de un verdadero mercado regional en el espacio de la Unión Europea. Ello ha supuesto libertad de entrada y salida y libre establecimiento de rutas, frecuencias, capacidades y precios por parte de las compañías aéreas, registradas y certificadas en cualquier estado miembro (Serrano, 1999).

Asimismo, cabe mencionar otros factores para el caso de España que justifican esta evolución favorable como la entrada en la todavía entonces Comunidad Económica Europea, la internacionalización de la economía en el contexto europeo y mundial, la creciente atracción turística, el afianzamiento como puente de conexión con los países iberoamericanos y el crecimiento del nivel de vida de la población, entre otras razones.

Respecto al tráfico nacional, en 1970 diez aeropuertos registraban un CCA superior a la media nacional $(18,4 \%)$. Se trataba de aquellas infraestructuras pertenecientes a las grandes ciudades del país (Madrid, Barcelona, Sevilla, Valencia), destinos turísticos de primera magnitud (Las Palmas de Gran Canaria, Tenerife, Palma de Mallorca, Málaga, Lanzarote) y ciudades como Santiago que servía a su área urbana-regional, en el noroeste del país (tabla 2). La conjunción de estos tres hechos, deben interpretarse como factores suficientes para la consecución de una densa red de enlaces aéreos, lo que justificaría su destacada conectividad, sobre todo, de Madrid y Barcelona al conectarse estas dos con la mayor parte de los aeropuertos españoles (figura 5).

Por debajo del citado umbral, pero no muy alejado de él (entre el 10\% y 18\%; tabla 3), se encuentran ciudades importantes en sus contextos regionales (Oviedo, Santander, Bilbao, A Coruña); destinos turísticos de gran predominio de la modalidad chárter (Alicante, Ibiza, Murcia-San Javier) y centros regionales como San Sebastián y Almería, en el norte y sur, respectivamente. Destaca también el caso singular de El Aaiún, todavía formando parte de la red nacional, hasta la Marcha Verde de 1975. Lejos de estos, el resto de nodos están bastante distanciados de la media nacional, al registrar tan sólo uno o dos enlaces aéreos nacionales (casi siempre con Madrid y/o Barcelona).

En 2015 la situación ha cambiado de manera notoria. Aparte de superar los 175 millones de pasajeros anuales (domésticos e internacionales; AENA, 2015), la organización de la red mostraba altos signos de madurez, pues tanto el grado de cohesión del sistema como el número de aeropuertos que se encontraban por encima de la conectividad media del sistema aumentan (tabla 4; figura 6). El proceso de liberalización del sector, la aparición de nuevas compañías, entre ellas las aerolíneas low cost, y la mayor competitividad aérea, bien pueden justificar este profundo cambio. En 2015, son quince los aeropuertos que gozan de un CCA por encima de la media (24,09\%). Además de los que ya figuraban en 1970, aparecen Bilbao, Asturias y Santander, que escalan posiciones al incrementar su número de enlaces con el resto de ciudades españolas. Junto a estos, Alicante, Ibiza y Menorca como importantes destinos turísticos ${ }^{6}$.

6 En 1970 tan sólo existía en Tenerife el aeropuerto de Los Rodeos (hoy conocido como Tenerife Norte). Sin embargo, las demandas del sector turístico y la saturación del anterior provocaron que en 1978 se inaugurara el aeropuerto Reina Sofía (hoy Tenerife Sur), consolidándose como el aeropuerto tinerfeño de mayor importancia internacional. 


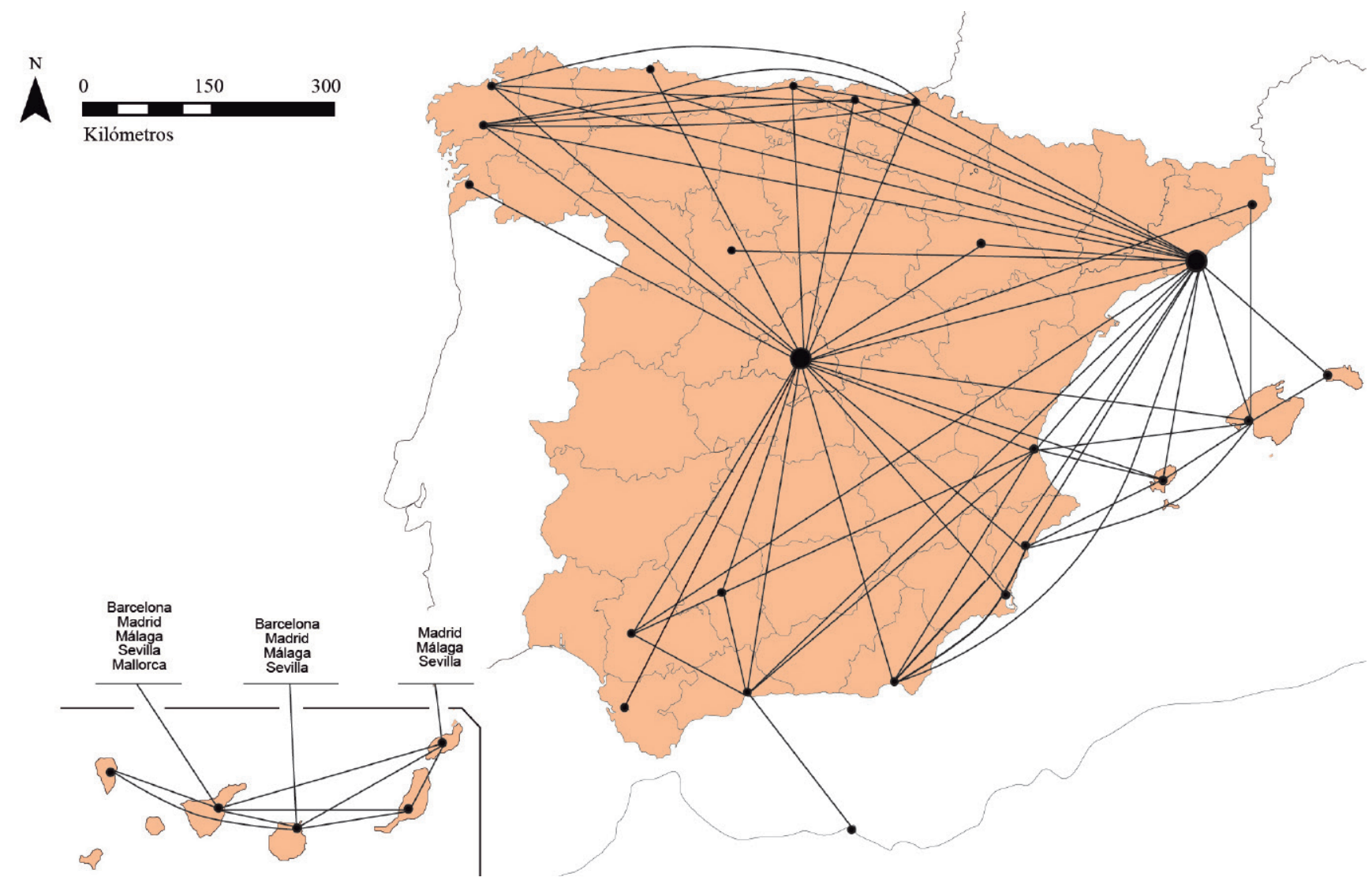

Figura 5. Red de conexiones aéreas domésticas en España, 1970. Fuente: Elaboración propia a partir de las Guías ABC-Comber International Guides -OAG.

Tabla 2. Aeropuertos con CCA nacional superior a la media del país (1970).

\begin{tabular}{|c|c|c|c|c|}
\hline \multirow{2}{*}{ Aeropuerto } & \multirow{2}{*}{$\mathrm{N}^{\circ}$ conexiones } & \multicolumn{3}{|c|}{ Coeficiente de Conectividad Ajustado (CCA) } \\
\hline & & $\mathrm{N}$ & $\mathrm{N}-1$ & CCA \\
\hline Madrid & 23 & 30 & 29 & 79,31 \\
\hline Barcelona & 20 & 29 & 28 & 71,43 \\
\hline Málaga & 10 & 28 & 27 & 37,04 \\
\hline Gran Canaria & 11 & 31 & 30 & 36,67 \\
\hline Sevilla & 8 & 29 & 28 & 28,57 \\
\hline Palma de Mallorca & 8 & 31 & 30 & 26,67 \\
\hline Tenerife & 8 & 31 & 30 & 26,67 \\
\hline Valencia & 7 & 29 & 28 & 25,00 \\
\hline Santiago & 6 & 29 & 28 & 21,43 \\
\hline Lanzarote & 6 & 31 & 30 & 20,00 \\
\hline
\end{tabular}

Fuente: Resultados de la investigación a partir de las Guías ABC-Comber International Guides -OAG. 
Tabla 3. Aeropuertos con CCA nacional entre 10 y 18\% (1970).

\begin{tabular}{|c|c|c|c|c|}
\hline \multirow{2}{*}{ Aeropuerto } & \multirow{2}{*}{$\mathrm{N}^{\circ}$ conexiones } & \multicolumn{3}{|c|}{ Coeficiente de Conectividad Ajustado (CCA) } \\
\hline & & $\mathrm{N}$ & $\mathrm{N}-1$ & CCA \\
\hline Alicante & 5 & 29 & 28 & 17,86 \\
\hline Almería & 5 & 29 & 28 & 17,86 \\
\hline San Sebastián & 5 & 29 & 28 & 17,86 \\
\hline Asturias & 5 & 30 & 29 & 17,24 \\
\hline Ibiza & 5 & 31 & 30 & 16,67 \\
\hline El Aaiún & 5 & 32 & 31 & 16,13 \\
\hline Santander & 4 & 28 & 27 & 14,81 \\
\hline A Coruña & 4 & 29 & 28 & 14,29 \\
\hline Bilbao & 4 & 30 & 29 & 13,79 \\
\hline Murcia & 3 & 28 & 27 & 11,11 \\
\hline
\end{tabular}

Fuente: Resultados de la investigación a partir de las Guías ABC-Comber International Guides -OAG.

Tabla 4. Aeropuertos con CCA nacional superior a la media del país (2015).

\begin{tabular}{|c|c|c|c|c|}
\hline \multirow{2}{*}{ Aeropuerto } & \multirow{2}{*}{$\mathrm{N}^{\circ}$ conexiones } & \multicolumn{3}{|c|}{ Coeficiente de Conectividad Ajustado (CCA) } \\
\hline & & $\mathrm{N}$ & $\mathrm{N}-1$ & CCA \\
\hline Madrid & 28 & 38 & 37 & 75,68 \\
\hline Barcelona & 27 & 37 & 36 & 75,00 \\
\hline Palma de Mallorca & 23 & 39 & 38 & 60,53 \\
\hline $\begin{array}{l}\text { Tenerife ( } 2 \\
\text { aeropuertos) }\end{array}$ & 20 & 39 & 38 & 52,63 \\
\hline Málaga & 17 & 36 & 35 & 48,57 \\
\hline Bilbao & 17 & 38 & 37 & 45,95 \\
\hline Gran Canaria & 16 & 39 & 38 & 42,11 \\
\hline Alicante & 15 & 37 & 36 & 41,67 \\
\hline Sevilla & 15 & 37 & 36 & 41,67 \\
\hline Ibiza & 15 & 39 & 38 & 39,47 \\
\hline Santiago & 14 & 37 & 36 & 38,89 \\
\hline Valencia & 14 & 37 & 36 & 38,89 \\
\hline Menorca & 14 & 39 & 38 & 36,84 \\
\hline Asturias & 13 & 38 & 37 & 35,14 \\
\hline Lanzarote & 13 & 39 & 38 & 34,21 \\
\hline Santander & 11 & 36 & 35 & 31,43 \\
\hline
\end{tabular}

Fuente: Resultados de la investigación a partir de las Guías ABC-Comber International Guides -OAG. 


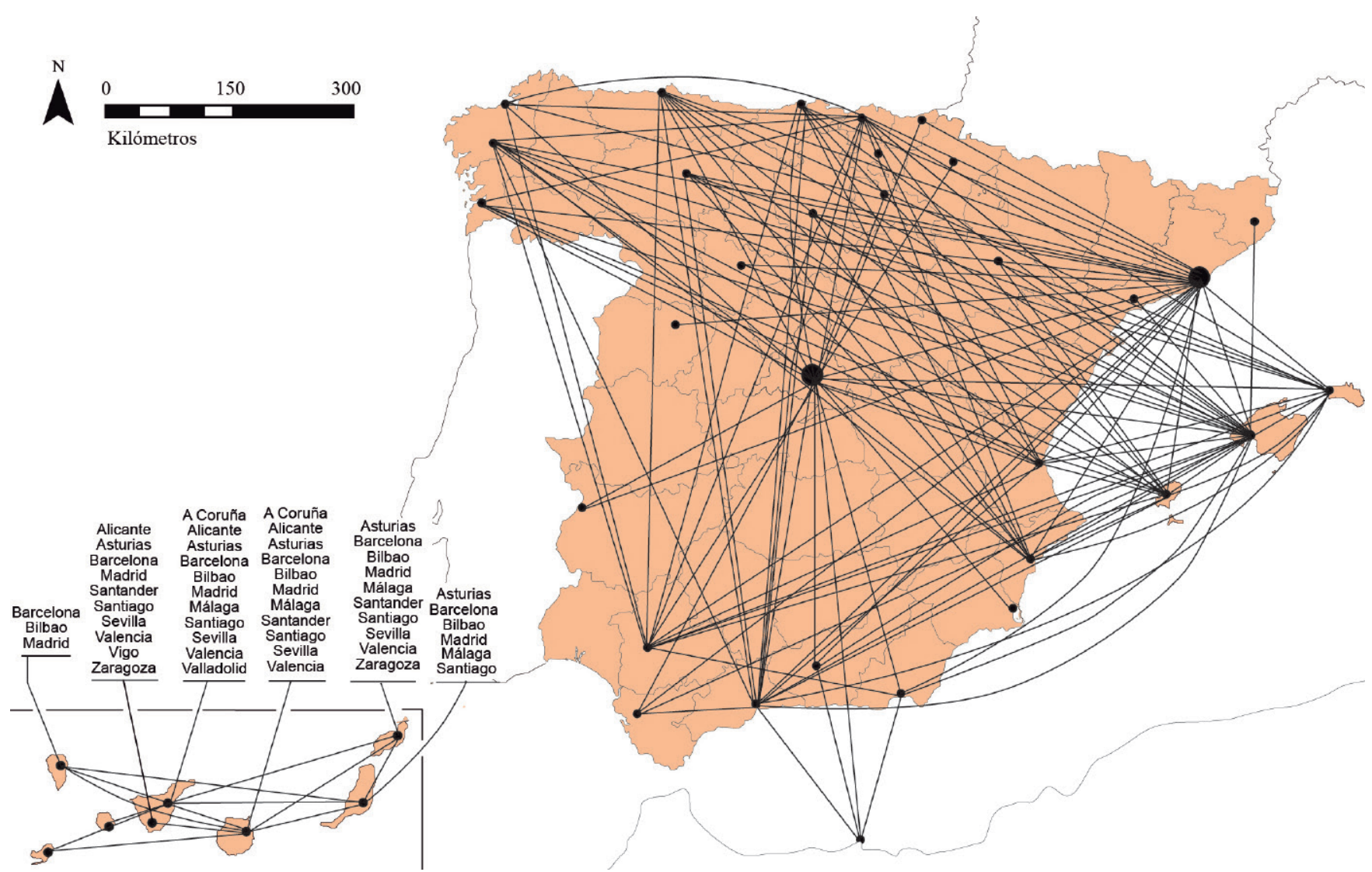

Figura 6. Red de conexiones aéreas domésticas en España, 2015. Fuente: Elaboración propia a partir de las Guías ABC-Comber International Guides -OAG.

Por debajo de ellos, otros tantos (entre el 10 y $24 \%$ de CCA). Aunque todavía no alcanzan la media, algunos han experimentado un gran avance respecto al año 1970 como Zaragoza, Valladolid, Reus y Jerez. Su número de enlaces aéreos nacionales se ha incrementado de manera constatable, bien por la consolidación de centros rectores de sus respectivas comunidades autónomas (Zaragoza y Valladolid), bien por el crecimiento de pequeñas ciudades que auspician la descongestión del tráfico aéreo de sus respectivos centros nodales (Reus para Barcelona y Jerez para Sevilla). Sin embargo, otros retroceden posiciones: en primer lugar, Fuerteventura ante la competencia de las capitales de las provincias canarias; pero, el caso más destacado es el fuerte retroceso de San Sebastián por la gran competencia aeroportuaria que ejerce Bilbao. En escalones inferiores, muchos de los pequeños aeropuertos regionales de segundo y tercer nivel cuyo tráfico de pasajeros es mayoritariamente nacional (Gámir \& Ramos, 2011). Es decir, aeropuertos cuya conectividad aérea se reduce casi exclusivamente con las tres principales instalaciones españolas (Madrid y/o Barcelona y/o Palma de Mallorca).

Sin embargo, es en el tráfico internacional donde se ha observado una profunda metamorfosis. En 1970, cuando en España existía todavía una gran regulación del tráfico aéreo e Iberia ejercía el rol de compañía de bandera con hub principal en Madrid, el tráfico internacional español estaba totalmente dirigido por la capital. De los 44 enlaces internacionales con los que España estaba comunicada en 1970, Madrid polarizaba 43 de los mismos. Por consiguiente, su CC era casi del 100\%. Solo nueve ciudades más contaban con algún enlace aéreo internacional-regular: Barcelona (6), Las Palmas de G.C. (6), Palma de Mallorca (5), Málaga (2), Valencia (2), Tenerife (1), Alicante (1), Sevilla (1) y Girona (1) (tabla 5). El resto de ciudades no registraban ninguna conexión fuera de nuestras fronteras, salvo los destinos turísticos (archipiélagos y costa mediterránea) pero tan sólo mediante vuelos chárter. De esta manera, si un pasajero quería ir al extranjero en avión en aquel entonces, debía pasar previamente por Madrid en la mayoría de los casos. Es, por esto, por lo que se considera que la red española estaba fuertemente polarizada. 
Tabla 5. Aeropuertos con mayor CC internacional (1970). Selección de casos.

\begin{tabular}{|l|c|c|c|}
\hline \multicolumn{1}{|c|}{ Aeropuerto } & $\begin{array}{c}N^{\circ} \text { conexiones aéreas } \\
\text { internacionales }\end{array}$ & $\begin{array}{c}N^{\circ} \text { aeropuertos } \\
\text { internacionales con } \\
\text { conexión desde España }\end{array}$ \\
\hline Madrid & 43 & 44 & 97,72 \\
\hline Barcelona & 6 & 44 & 13,63 \\
\hline Gran Canaria & 6 & 44 & 13,63 \\
\hline Palma de Mallorca & 5 & 44 & 4,36 \\
\hline Málaga & 2 & 44 & 4,54 \\
\hline Valencia & 2 & 44 & 2,27 \\
\hline Alicante & 1 & 44 & 2,27 \\
\hline Girona & 1 & 44 & 2,27 \\
\hline Sevilla & 1 & 44 & 2,27 \\
\hline Tenerife & 1 & 44 & 27 \\
\hline
\end{tabular}

Fuente: Resultados de la investigación a partir de las Guías ABC-Comber International Guides -OAG.

En 2015, puede decirse que la situación es muy diferente, con 222 destinos internacionales más que en 1970. Algunos rasgos explicativos se encuentran en el importante proceso de internacionalización económica y la liberalización comercial (Villarrolla et al., 2006) y también en relación con el desarrollo del sector turístico (Vizcaíno, 2015). El transporte aéreo es, así, un indicador de la creciente presencia internacional de España.

La transformación del sector aéreo también se ha visto favorecida por una adaptación importante de las demandas de movilidad y de la creciente competencia entre las aerolíneas. Se asiste al proceso de privatización de la compañía de bandera (Iberia) en 1999, la liberalización de la actividad y el nacimiento de las compañías de bajo coste (CBC) que, con su modelo de actuación muy flexible basado en el "punto a punto", han multiplicado el número de aeropuertos emisores y receptores (Wensveen \& Leick, 2009).

En 2015 España está conectada con un total de 266 aeropuertos internacionales y, aunque Madrid y Barcelona siguen teniendo los CC más elevados, ahora la conectividad topológica está más repartida (tabla 6). Es decir, hay muchos otros aeropuertos que tienen conexión fuera de nuestras fronteras, de tal manera que su inserción en las corrientes globalizadoras se ha materializado e intensificado, aunque conviene matizar que esta apertura está intensamente focalizada en el viejo continente. Tan solo Madrid, como principal hub de conexión de España con el resto del mundo, está conectada con otras grandes regiones mundiales, especialmente con Latinoamérica, África y Asia. Por otra parte, Barcelona aunque goza de un CC superior a Madrid, no ejerce de gran hub intercontinental, aunque que ha visto incrementar sus conexiones internacionales de manera sobresaliente, especialmente con América y con el margen africano de la cuenca mediterránea (Díez-Pisonero, 2016).

Por debajo de ellas, otras tantas ciudades cuentan con un CC superior a la media nacional por tratarse de destacados destinos turísticos, bien de los archipiélagos (Palma de Mallorca, Tenerife, Gran Canaria y Fuerteventura), bien de la costa mediterránea (Málaga, Alicante, Valencia). Junto a ellos Girona cuya participación en el mercado internacional, tras el "efecto Ryanair", creció exponencialmente. En rangos inferiores otros aeropuertos que, a pesar de contabilizar unos CC por debajo de la media nacional, han experimentado una apertura internacional considerable gracias a las CBC (Serrano \& García, 2015). El número de conexiones internacionales de estas infraestructuras no alcanza los niveles de los principales aeropuertos españoles pero, si comparamos su situación respecto a 1970, supone un cambio considerable.

7 El aeropuerto de Girona ha desempeñado una función de hub para la aerolínea de bajo coste Ryanair que fijó esta localización como base de operaciones en 2004. 
Tabla 6. Aeropuertos con mayor CC internacional (2015). Selección de los 10 primeros.

\begin{tabular}{|l|c|c|c|}
\hline \multicolumn{1}{|c|}{ Aeropuerto } & $\begin{array}{c}N^{\circ} \text { conexiones aéreas } \\
\text { internacionales }\end{array}$ & $\begin{array}{c}N^{\circ} \text { aeropuertos } \\
\text { internacionales con } \\
\text { conexión desde España }\end{array}$ & CC \\
\hline Barcelona & 159 & 266 & 53,77 \\
\hline Madrid & 142 & 266 & 44,73 \\
\hline Palma de Mallorca & 119 & 266 & 32,70 \\
\hline Málaga & 87 & 266 & 32,33 \\
\hline Alicante & 86 & 266 & 28,19 \\
\hline Gran Canaria & 75 & 266 & 26,69 \\
\hline Tenerife (2 aeropuertos) & 71 & 266 & 23,30 \\
\hline Ibiza & 62 & 266 & 17,66 \\
\hline Fuerteventura & 47 & 266 & 16,54 \\
\hline Menorca & 44 & 266 & 2 \\
\hline
\end{tabular}

Fuente: Resultados de la investigación a partir de las Guías ABC-Comber International Guides -OAG.

\section{IMPACTO DE LA COVID-19 EN LA RED AEROPORTUARIA ESPAÑOLA: ¿UNA TRAYECTORIA TRUNCADA?}

La actual crisis sanitaria motivada por la pandemia de la COVID-19 está teniendo un profundo impacto en toda la industria aeronáutica. Como se ha presentado en el apartado 2 , sus consecuencias han supuesto un duro golpe a nivel global y regional y, por supuesto, estas también se han sentido y se siguen apreciando a escala nacional. Como dato ilustrativo, cabe mencionar la tónica ascendente generalizada tanto en número de pasajeros como número de operaciones en los aeropuertos españoles entre 2015-2019, salvo Salamanca y Murcia, y la profunda caída de las métricas entre 2019-2020, extendida a todas las infraestructuras, a excepción de casos puntuales de relevancia menor (figura 7). En términos globales, y según datos de AENA (2021), en 2020 los pasajeros en vuelos domésticos supusieron un total de 76.065.000, con una reducción del $(-72,4 \%)$ con respecto a 2019. Las operaciones comerciales nacionales se redujeron en proporción menor $(-48,5 \%)$, lo que indica, desde nuestro punto de vista, cómo el servicio se garantizó proporcionando una conectividad mínima a pesar de la reducción drástica de la demanda.

El impacto para el caso concreto del movimiento de viajeros en los aeropuertos españoles (figura 8; tabla 7) es evidente en cuanto a la ruptura de la trayectoria ascendente que se venía produciendo desde 2019. Así, el volumen de pasajeros para el verano de 2020 es considerablemente menor al del año anterior, no habiéndose alcanzado tampoco la "esperada recuperación en el verano de 2021", aunque sí se observa un crecimiento evidente con respecto al primer año de la pandemia. Esta trayectoria nos habla ya de un impacto de largo alcance y, por lo menos para el caso de España, de un proceso de recuperación lento.

Para valorar el peso del turismo en la evolución de la demanda aeroportuaria se ha elaborado la ya citada tabla 7, referida a los meses de julio y agosto. En este sentido, sí se observan algunos patrones diferenciados dependiendo de los aeropuertos. Por ejemplo, caídas algo menos pronunciadas en algunos de los insulares entre el verano de 2019 y el de 2020, fundamentalmente en las Islas Canarias (Tenerife Norte y La Palma), que debe ponerse en relación con la activación del turismo nacional en el verano de 2020. También, unas tasas de variación menos negativas que en el conjunto del sistema en un periodo más amplio (entre 2019 y 2021), en algunos destinos de sol y playa ligados tanto a una demanda nacional como internacional: Palma de Mallorca, Málaga, Gran Canaria, Ibiza, Valencia, Tenerife Norte, Menorca, La Palma, Fuerteventura. A ello, se unen aeropuertos de interior, que muestran una tendencia clara de recuperación (aunque todavía 
con niveles inferiores a la situación prepandémica). Es especialmente notorio el caso de los aeropuertos de Santiago y Asturias, aunque en el grupo de aeropuertos con tasas de recuperación superiores a la media también se encuentran Valencia, Sevilla, Bilbao y A Coruña.

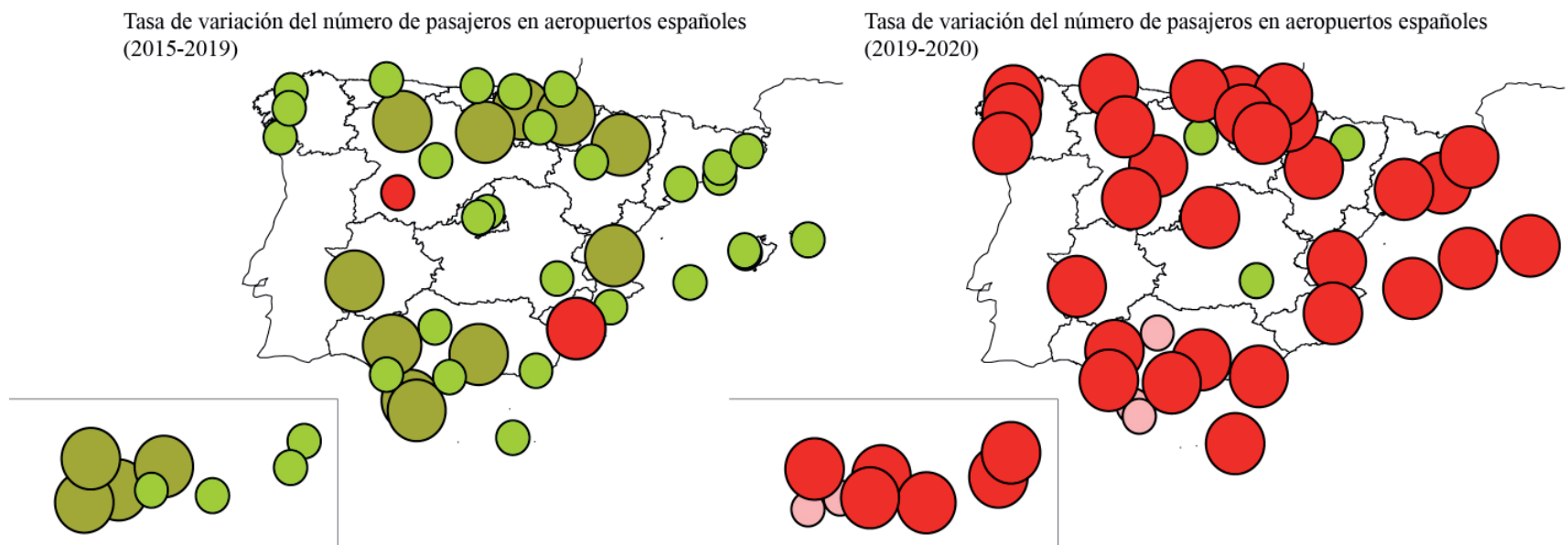

Tasa de variación del número de operaciones en aeropuertos españoles (2015-2019)

Tasa de variación del número de pasajeros en aeropuertos españoles (2019-2020)
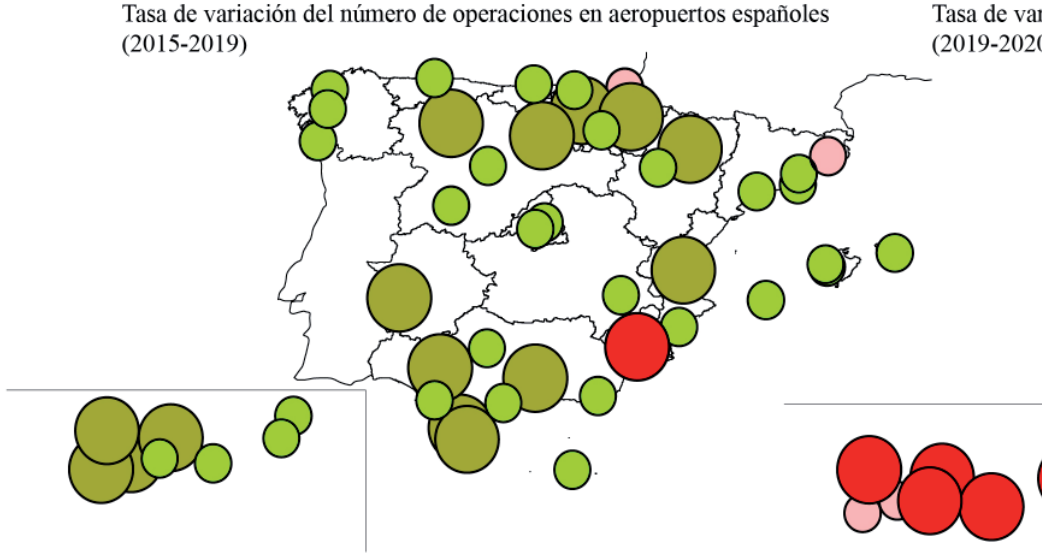

Tasa de variación del número de operaciones en aeropuertos españoles 2019-2020)
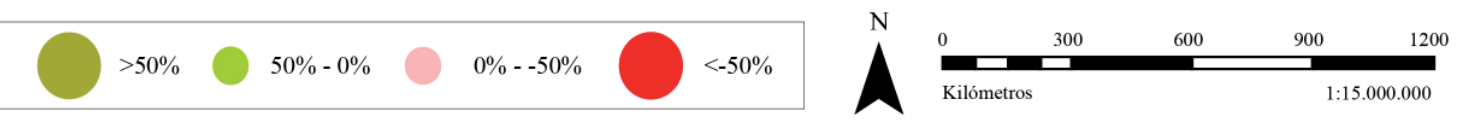

Figura 7. Tasa de variación de pasajeros y operaciones aéreas en aeropuertos españoles (2015-2019 y 2019-2020). Fuente: Elaboración propia a partir de datos de AENA (2015, 2019, 2020).

Los grandes aeropuertos nacionales (Madrid y Barcelona), con una demanda más diversificada en cuanto al perfil del usuario (sector MICE, recepción de trabajadores, inmigrantes) y su función de hub, muestran un proceso de recuperación más débil, coherente con la coyuntura internacional. Es patente la escasa recuperación del aeropuerto de Girona, debido a la casi absoluta supresión de la actividad de la compañía Ryanair en este último, que cumplía funciones logísticas y de hub. Por último, es destacable también la escasa y lenta recuperación de la actividad en Tenerife-Sur, en relación con una dependencia muy alta de la demanda internacional, aunque debe tenerse en cuenta que la temporada alta de turismo en el sur de la Isla de Tenerife no coincide con los meses estivales.

Los datos con respecto a los indicadores de movilidad en los veranos de 2020 y 2021 son, así, coherentes con la dinámica de movilidad ligada a la crisis de la pandemia. En la primera ola y no solo para España, el cierre de las fronteras decretados progresivamente por los gobiernos de todo el mundo para contener el brote de la COVID-19 derivó en una promoción del turismo doméstico y de la movilidad nacional. 
En este sentido, en junio de 2020 y para el turismo nacional se "anticipaba una primera recuperación de la demanda doméstica de proximidad, aunque condicionada por una mayor preferencia hacia instalaciones turísticas de menor tamaño (casas rurales, pequeños establecimientos) y/o gratuito (segundas residencias, familiares y amigos) y el vehículo privado como medio de desplazamiento" (...). Las caídas más intensas del sector turístico se observaron en aquellos destinos "más expuestos a mercados internacionales, muy condicionados por las restricciones de movilidad, las garantías sanitarias entre países y el fenómeno de la staycation" (Exceltur, 2020, pp. 6 y 7). Es decir, la paulatina recuperación de la actividad aérea tras el confinamiento estricto de marzo se focalizó especialmente en el mercado doméstico, que vio como las conexiones o rutas se restablecía en verano al configurarse una red en estructura similar a la prepandémica (tablas 7, 8 y 9. figura 9). No obstante, las pérdidas han sido importantes tanto en relación con la pérdida global de pasajeros como de frecuencias, aunque con una cierta recuperación de la caída en 2021 (tabla 7).

Tabla 7. Tasa de variación del total de pasajeros en los aeropuertos españoles en los veranos. 2019-2020 y 2019-2021. (Datos referidos únicamente a los meses de julio y agosto).

\begin{tabular}{|c|c|c|}
\hline Aeropuerto & $2019-2020$ & 2019-2021 \\
\hline Total & $-72,93$ & $-43,71$ \\
\hline A.S. Madrid-Barajas & $-80,00$ & $-52,90$ \\
\hline Barcelona-Prat & $-81,59$ & $-52,42$ \\
\hline Palma-Mallorca & $-72,40$ & $-40,11$ \\
\hline Málaga & $-71,73$ & $-42,74$ \\
\hline Alicante-Elche & $-73,53$ & $-50,59$ \\
\hline Gran Canaria & $-60,43$ & $-32,98$ \\
\hline Tenerife-Sur & $-77,16$ & $-51,01$ \\
\hline Ibiza & $-63,04$ & $-28,32$ \\
\hline Valencia & $-65,53$ & $-31,00$ \\
\hline Sevilla & $-65,32$ & $-31,02$ \\
\hline Lanzarote & $-64,68$ & $-39,46$ \\
\hline Tenerife Norte & $-39,70$ & $-15,31$ \\
\hline Fuerteventura & $-57,25$ & $-30,55$ \\
\hline Bilbao & $-68,34$ & $-34,76$ \\
\hline Menorca & $-60,16$ & $-19,65$ \\
\hline Santiago & $-60,89$ & $-15,68$ \\
\hline La Palma & $-39,67$ & $-18,61$ \\
\hline Asturias & $-55,33$ & $-13,74$ \\
\hline Girona & $-87,80$ & $-77,86$ \\
\hline A Coruña & $-73,07$ & $-39,20$ \\
\hline Resto aeropuertos red comercial & $-72,57$ & $-46,16$ \\
\hline
\end{tabular}

Fuente: Resultados de la investigación a partir de las estadísticas de AENA, 2019-2021. 
--A.S. Madrid-Barajas

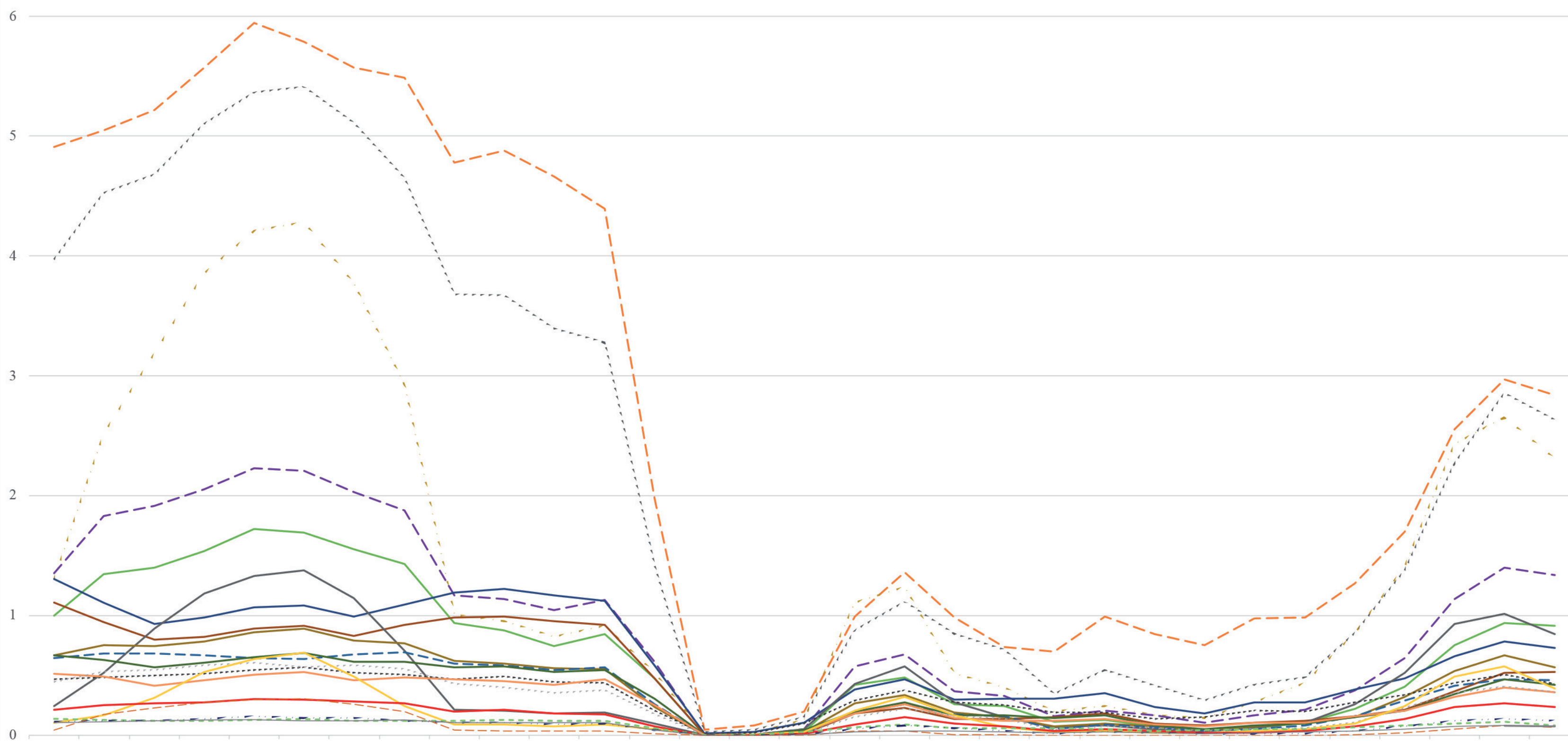

Barcelona-Pra

- -Palma-Mallorca

--Málaga

—Alicante-Elche

- Gran Canaria

— Tenerife-Sur

—Ibiza

—Valencia

- -Sevilla

- Lanzarote

-.-.-Tenerife Norte

-Fuerteventura

---Bilbao

-Menorca

-Santiago

- -La Palma

$-\cdot \cdot$ Asturias

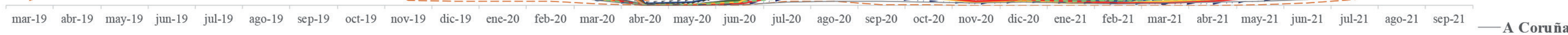

Figura 8. Evolución del volumen de pasajeros en aeropuertos españoles. Marzo 2019 a septiembre 2021. Fuente: Resultados de la investigación a partir de las estadísticas de AENA, 2019- 2020. 


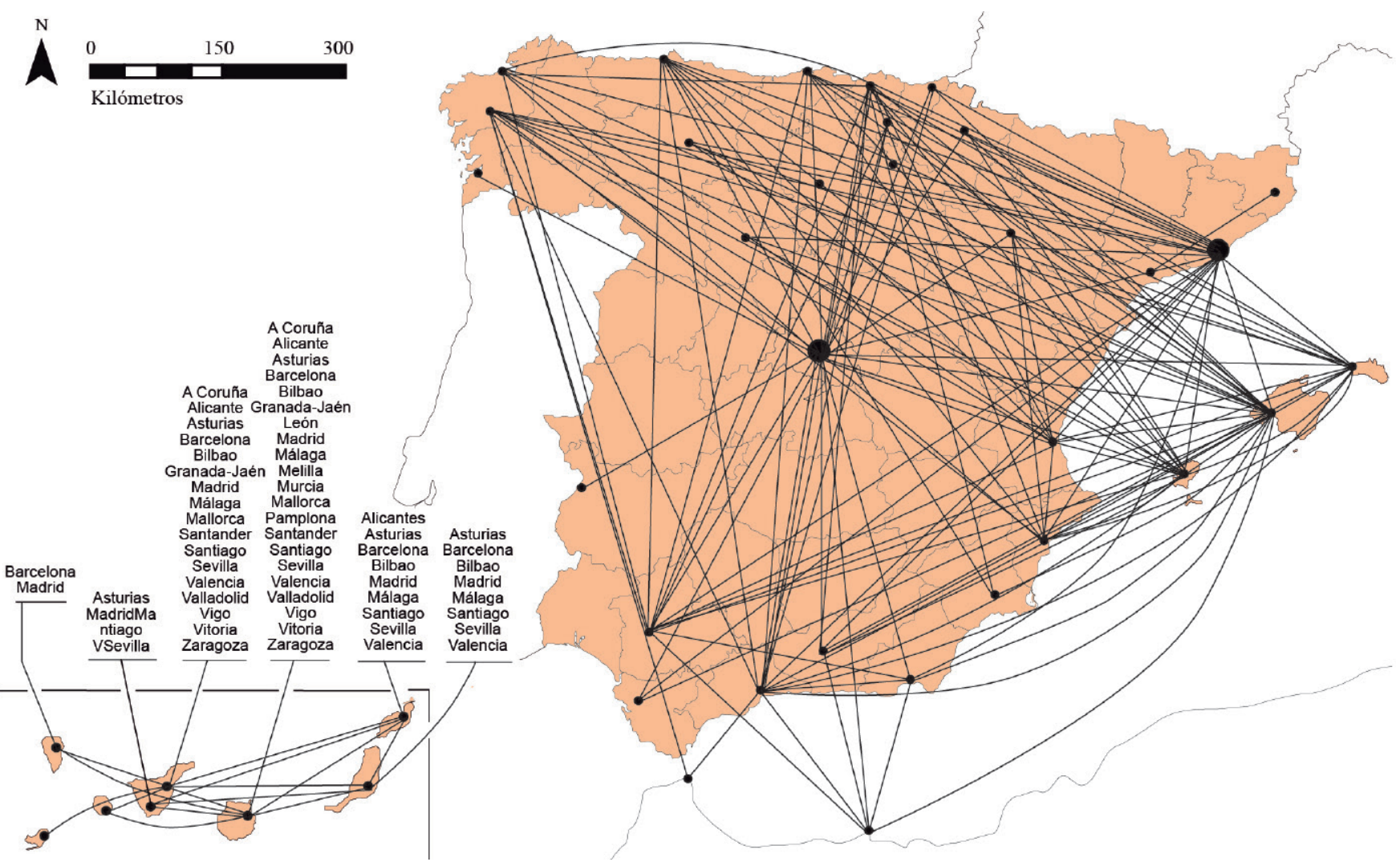

Figura 9. Red de conexiones aéreas domésticas en España, 2020, agosto. Fuente: Resultados de la investigación a partir de las Guías ABC-Comber International Guides-OAG.

El descenso de frecuencias también ha sido muy acusado. La tabla 8 recoge las principales rutas domésticas en los años estudiados. En esta tabla se aprecia un doble aspecto: i) una treintena de rutas en relación con la conectividad de los dos hub principales (Madrid y Barcelona, en colores amarillo y azulado) y los destinos insulares (en verde) polarizan una proporción considerable de las frecuencias totales anuales (por encima del $60 \%$ en ambas fechas), cuestión que es interesante pero no está relacionada con la pandemia, más bien con la funcionalidad del sistema; ii) todas estas rutas experimentaron durante el 2020 pérdidas importantes con respecto al año anterior (-48,5\%, como promedio), siendo los destinos insulares (entre las Islas de Canarias y la ruta Ibiza- Palma de Mallorca) aquellos que mostraron decrecimientos, aunque significativos, por debajo de la media.

Así, el restablecimiento del tráfico doméstico en 2020, tras el severo confinamiento de primavera, adquiere gran interés. Es decir, se reestablecieron las rutas, aun con una demanda considerablemente menor, y no solo en aquellas localizaciones donde el concurso del transporte aéreo es más necesario y efectivo para el desenclave (destinos insulares). Esto se observa en gran parte de la red aeroportuaria, en aquellos aeropuertos con un CCA superior a la media nacional (33,2\%; tabla 9): (i) Madrid y Barcelona, con CCA superiores al $80 \%$, al tratarse de los dos grandes aeropuertos de la jerarquía aeroportuaria española; (ii) los aeropuertos con funcionalidad turística destacada en ambos archipiélagos y en la costa mediterránea, como Gran Canaria (82,35\%), Palma de Mallorca (76,47\%), Tenerife (67,65\%), Valencia (67,65\%), Málaga (58,06\%), Ibiza (50\%), Menorca (44\%), Lanzarote (38,24\%); y (iii) ciudades importantes de la jerarquía urbana que sirven a sus áreas urbano-regionales como Sevilla (59,38\%), Bilbao $(54,55 \%)$, Santiago $(46,48 \%)$, Asturias $(45,45 \%)$ y Zaragoza (39,39\%). Otros aeropuertos de carácter regional, aunque con CCA inferiores a la media, también presentan coeficientes de conexión adecuados, como Pamplona, Valladolid, San Sebastián y A Coruña, entre otros. 
Tabla 8. Evolución de las principales rutas domésticas en España (frecuencias 2019 y 2020).

\begin{tabular}{|c|c|c|c|c|c|}
\hline \multirow[b]{2}{*}{ RUTA (Ida y vuelta) } & \multicolumn{2}{|c|}{2019} & \multicolumn{2}{|c|}{2020} & \multirow{2}{*}{$\begin{array}{c}\text { \% variación } \\
\text { frecuencias } \\
\text { totales. } \\
2019-2020\end{array}$} \\
\hline & $\begin{array}{c}\text { Total } \\
\text { frecuencias } \\
\text { anuales }\end{array}$ & $\begin{array}{l}\% \text { respecto } \\
\text { al total de las } \\
\text { frecuencias }\end{array}$ & $\begin{array}{c}\text { Total } \\
\text { frecuencias } \\
\text { anuales }\end{array}$ & $\begin{array}{l}\% \text { respecto } \\
\text { al total de las } \\
\text { frecuencias }\end{array}$ & \\
\hline A Coruña- Madrid & 5762 & 1,40 & 2360 & 1,11 & $-59,04$ \\
\hline Alicante- Madrid & 4161 & 1,01 & 1674 & 0,79 & $-59,77$ \\
\hline Asturias- Madrid & 5461 & 1,33 & 1961 & 0,93 & $-64,09$ \\
\hline Barcelona- Bilbao & 4405 & 1,07 & 1827 & 0,86 & $-58,52$ \\
\hline Barcelona- Ibiza & 8700 & 2,11 & 4241 & 2,00 & $-51,25$ \\
\hline Barcelona- Madrid & 16878 & 4,10 & 6511 & 3,07 & $-61,42$ \\
\hline Barcelona- Málaga & 5088 & 1,24 & 2512 & 1,19 & $-50,63$ \\
\hline Barcelona- Menorca & 6284 & 1,53 & 3720 & 1,76 & $-40,80$ \\
\hline Barcelona- Sevilla & 6532 & 1,59 & 2790 & 1,32 & $-57,29$ \\
\hline Barcelona-Palma de Mallorca & 15906 & 3,86 & 7781 & 3,67 & $-51,08$ \\
\hline Bilbao- Madrid & 7074 & 1,72 & 2696 & 1,27 & $-61,89$ \\
\hline El Hierro- Tenerife & 3645 & 0,89 & 2988 & 1,41 & $-18,02$ \\
\hline Fuerteventura- Gran Canaria & 12993 & 3,16 & 7831 & 3,70 & $-39,73$ \\
\hline Fuerteventura- Tenerife & 5181 & 1,26 & 3443 & 1,62 & $-33,55$ \\
\hline Gran Canaria-Lanzarote & 15248 & 3,70 & 8907 & 4,20 & $-41,59$ \\
\hline Gran Canaria-Madrid & 9704 & 2,36 & 5156 & 2,43 & $-46,87$ \\
\hline Gran Canaria-Tenerife & 22898 & 5,56 & 12446 & 5,87 & $-45,65$ \\
\hline Ibiza- Madrid & 7268 & 1,77 & 3710 & 1,75 & $-48,95$ \\
\hline Ibiza- Palma de Mallorca & 9758 & 2,37 & 5330 & 2,52 & $-45,38$ \\
\hline La Palma- Tenerife & 15172 & 3,69 & 8931 & 4,21 & $-41,13$ \\
\hline Lanzarote- Madrid & 3161 & 0,77 & 1590 & 0,75 & $-49,70$ \\
\hline Lanzarote- Tenerife & 7035 & 1,71 & 4486 & 2,12 & $-36,23$ \\
\hline Madrid- Málaga & 4668 & 1,13 & 2209 & 1,04 & $-52,68$ \\
\hline Madrid- Menorca & 2881 & 0,70 & 1626 & 0,77 & $-43,56$ \\
\hline Madrid- Palma de Mallorca & 14095 & 3,42 & 6986 & 3,30 & $-50,44$ \\
\hline Madrid- Sevilla & 5319 & 1,29 & 2003 & 0,95 & $-62,34$ \\
\hline Madrid-Tenerife & 11230 & 2,73 & 5030 & 2,37 & $-55,21$ \\
\hline Madrid- Valencia & 5602 & 1,36 & 2540 & 1,20 & $-54,66$ \\
\hline Madrid- Vigo & 5839 & 1,42 & 2003 & 0,95 & $-65,70$ \\
\hline Menorca- Palma de Mallorca & 7843 & 1,91 & 3997 & 1,89 & $-49,04$ \\
\hline Palma de Mallorca- Valencia & 5979 & 1,45 & 2916 & 1,38 & $-51,23$ \\
\hline CONEXIONES ACUMULADAS & 261770 & 63,60 & 132201 & 62,38 & \\
\hline TOTAL CONEXIONES ANUALES* & 411587 & & 211928 & & $-48,51$ \\
\hline
\end{tabular}

Fuente: Resultados de la investigación a partir de estadísticas de AENA, 2019 y 2020. 
Tabla 9. Aeropuertos con CCA nacional superior a la media del país (2020).

\begin{tabular}{|c|c|c|c|c|}
\hline \multirow{2}{*}{ Aeropuerto } & \multirow{2}{*}{$\mathrm{N}^{\circ}$ conexiones } & \multicolumn{3}{|c|}{ Coeficiente de Conectividad Ajustado (CCA) } \\
\hline & & $\mathrm{N}$ & $\mathrm{N}-1$ & CCA \\
\hline Madrid & 30 & 34 & 33 & 90,91 \\
\hline Barcelona & 27 & 33 & 32 & 84,38 \\
\hline Gran Canaria & 28 & 35 & 34 & 82,35 \\
\hline Palma de Mallorca & 26 & 35 & 34 & 76,47 \\
\hline Tenerife & 23 & 35 & 34 & 67,65 \\
\hline Sevilla & 19 & 33 & 32 & 59,38 \\
\hline Málaga & 18 & 32 & 31 & 58,06 \\
\hline Bilbao & 18 & 34 & 33 & 54,55 \\
\hline Valencia & 17 & 33 & 32 & 53,13 \\
\hline Ibiza & 17 & 35 & 34 & 50,00 \\
\hline $\begin{array}{l}\text { Santiago de } \\
\text { Compostela }\end{array}$ & 15 & 33 & 32 & 46,88 \\
\hline Asturias & 15 & 34 & 33 & 45,45 \\
\hline Menorca & 15 & 35 & 34 & 44,12 \\
\hline Alicante & 14 & 33 & 32 & 43,75 \\
\hline Zaragoza & 13 & 34 & 33 & 39,39 \\
\hline Lanzarote & 13 & 35 & 34 & 38,24 \\
\hline
\end{tabular}

Fuente: Resultados de la investigación.

Aunque el shock en la movilidad del sistema de transporte aéreo español durante la primera ola de la pandemia fue generalizado, tanto a escalas nacional como internacional, pretendemos en las siguientes líneas ahondar en el comportamiento específico de la movilidad aérea internacional. En relación con las cifras de 2019, España perdió en 2020 alrededor de 147,3 millones de pasajeros internacionales, lo que supuso un decrecimiento de aproximadamente el $77,76 \%$ del volumen del año anterior (tabla 10). Se trata de una cifra muy alta, y casi todos los aeropuertos importantes experimentaron pérdidas superiores al $70 \%$. En líneas generales, la proporción de pérdidas de pasajeros fue menor en el tráfico doméstico, aunque debe señalarse que este solo suponía el 30\% aproximadamente del total.

Destacan localizaciones con pérdidas significativamente superiores a la media, como Girona (instalación que respondía mayoritariamente a la demanda extranjera), Ibiza, Málaga, Menorca y Palma de Mallorca. Estos últimos aeropuertos perdieron, en proporción, menos viajeros domésticos, con cifras inferiores a las pérdidas medias del país: Palma de Mallorca (-46,3\%), Menorca, Fuerteventura y Lanzarote (-48\%), y Gran Canaria, Ibiza y Málaga, también por debajo de la media del conjunto. Este hecho incide en una idea ya indicada en líneas anteriores, en relación con el papel que ha jugado la demanda interior en el mantenimiento de la actividad del sector aéreo.

Resulta también relevante hacer referencia a la evolución de la conectividad para valorar en qué medida los aeropuertos perdieron conexiones internacionales, ligados a la escasa demanda inducida por las recomendaciones sanitarias en origen (tabla 10). Los resultados en relación con el mantenimiento de las rutas aéreas exteriores son algo menos negativos que lo que podrían anticipar los datos relativos al volumen de viajeros. Ciertamente, los aeropuertos sufrieron una pérdida de conectividad entre los veranos de 2019 y 
2020, pero no de una manera tan alarmante como las cifras de pasajeros y frecuencias. Las pérdidas de CC más significativas se dieron en los dos grandes aeropuertos del Estado, Madrid y Barcelona, que son aquellos que concentran gran parte de los vuelos transcontinentales, respondiendo a un amplio espectro de la demanda (tabla 10). La figura 10 muestra la variación de las frecuencias aéreas entre Madrid y Barcelona y los 20 destinos internacionales con mayor conectividad aérea de cada una de esas ciudades. En el caso de Madrid, por ejemplo, puede anotarse cómo en el verano de 2020 las principales rutas internacionales del 2019 continuaban operativas, aunque, experimentaron decrecimientos en la frecuencia superiores al 60\%.

Por otra parte, se observa que los aeropuertos con vocación turística tuvieron caídas de la conectividad internacional (CC) más moderadas. Cabe sospechar, en este sentido, que se trata de una estrategia comercial de las aerolíneas, manteniendo la ruta, aunque reduciendo las frecuencias, ya que en el proceso también influye la necesidad de mantener los slots 8 .

Tabla 10. Aeropuertos con CCA internacional superior a la media del país (2020). Coeficientes de conectividad 2019 y 2020, verano. Número de nodos internacionales para determinar el CC=259.

\begin{tabular}{|c|c|c|c|c|c|c|}
\hline Aeropuerto & $\begin{array}{c}\text { No conexiones } \\
\text { aéreas } \\
\text { internacionales. } \\
2019\end{array}$ & $\begin{array}{l}\text { No conexiones } \\
\text { aéreas } \\
\text { internacionales. } \\
2020\end{array}$ & $\begin{array}{l}\text { CC Internac. } \\
2019\end{array}$ & $\begin{array}{l}\text { CC Internac. } \\
2020\end{array}$ & $\begin{array}{c}\text { \% variación } \\
\text { pasajeros } \\
\text { internacionales } \\
(2019-2020)\end{array}$ & $\begin{array}{c}\% \text { variación } \\
\text { pasajeros } \\
\text { nacionales } \\
(2019-2020)\end{array}$ \\
\hline $\begin{array}{l}\text { TOTAL AEROP. } \\
\text { ESPAÑA }\end{array}$ & & & & & $-77,76$ & $-60,47$ \\
\hline Alicante & 86 & 79 & 33,20 & 30,50 & $-76,28$ & $-66,41$ \\
\hline Barcelona & 159 & 106 & 61,39 & 40,93 & $-79,51$ & $-65,65$ \\
\hline Fuerteventura & 47 & 41 & 18,15 & 15,83 & $-68,00$ & $-48,03$ \\
\hline Girona & 37 & 32 & 14,29 & 12,36 & $-91,49$ & $-12,20$ \\
\hline Gran Canaria & 75 & 49 & 28,96 & 18,92 & $-68,17$ & $-52,92$ \\
\hline Ibiza & 62 & 54 & 23,94 & 20,85 & $-86,71$ & $-55,89$ \\
\hline Lanzarote & 42 & 37 & 16,22 & 14,29 & $-72,99$ & $-48,10$ \\
\hline Madrid & 142 & 104 & 54,83 & 40,15 & $-75,34$ & $-64,05$ \\
\hline Málaga & 87 & 87 & 33,59 & 33,59 & $-86,52$ & $-58,47$ \\
\hline Menorca & 44 & 35 & 16,99 & 13,51 & $-89,90$ & $-49,59$ \\
\hline $\begin{array}{l}\text { Palma de } \\
\text { Mallorca }\end{array}$ & 119 & 105 & 45,95 & 40,54 & $-93,60$ & $-46,34$ \\
\hline Sevilla & 57 & 40 & 22,00 & 15,44 & $-75,02$ & $-63,31$ \\
\hline \multirow[t]{3}{*}{$\begin{array}{l}\text { Tenerife** } \\
\text { (destino) }\end{array}$} & 71 & 60 & 27,41 & 23,17 & & \\
\hline & Tenerife Norte & & & & $-80,79$ & $-51,72$ \\
\hline & Tenerife Sur & & & & $-69,06$ & $-74,55$ \\
\hline Valencia & 35 & 55 & 13,51 & 21,24 & $-74,64$ & $-60,25$ \\
\hline $\begin{array}{l}\text { Resto aerop. } \\
\text { españoles }\end{array}$ & & & & & $-86,86$ & $-63,51$ \\
\hline
\end{tabular}

Fuente: Resultados de la investigación a partir de Comber International Guides -OAG para el cálculo del CC; Ministerio de Transportes, Movilidad y Agenda urbana 2021 en relación al volumen de pasajeros nacional e internacional.

8 El reglamento 95/93 de la UE exige que las aerolíneas que operan en aeropuertos coordinados (donde la demanda excede la capacidad durante periodos de tiempo significativos y resulta imposible resolver la situación a corto plazo) cumplan con un $80 \%$ de ejecución sobre la programación en cada ruta, medida en series de cinco slots (Cinco Días, 2021). 
Tasa de variación del número de frecuencias mensuales (2015-2019). Selección de los 20 destinos con mayor conectividad aérea desde Madrid

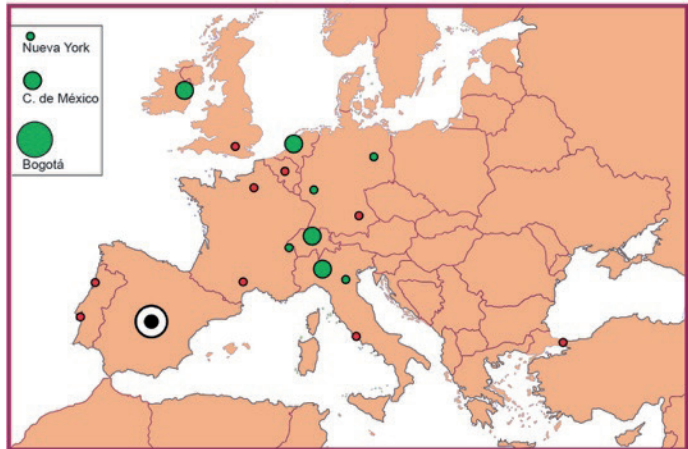

Tasa de variación del número de frecuencias mensuales (2015-2019). Selección de los 20 destinos con mayor conectividad aérea desde Barcelona

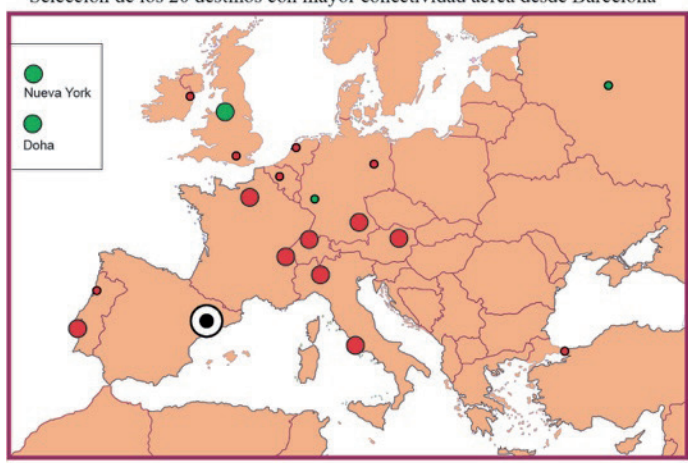

Tasa de variación del número de frecuencias mensuales (2019-2020). Selección de los 20 destinos con mayor conectividad aérea desde Madrid

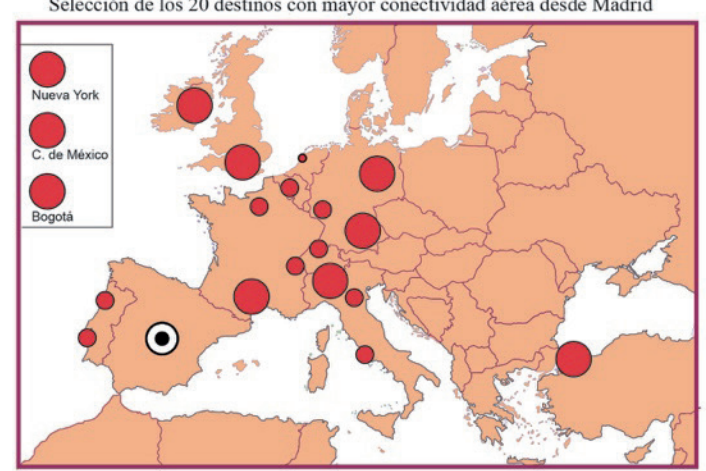

Tasa de variación del número de frecuencias mensuales (2019-2020). Selección de los 20 destinos con mayor conectividad aérea desde Barcelona

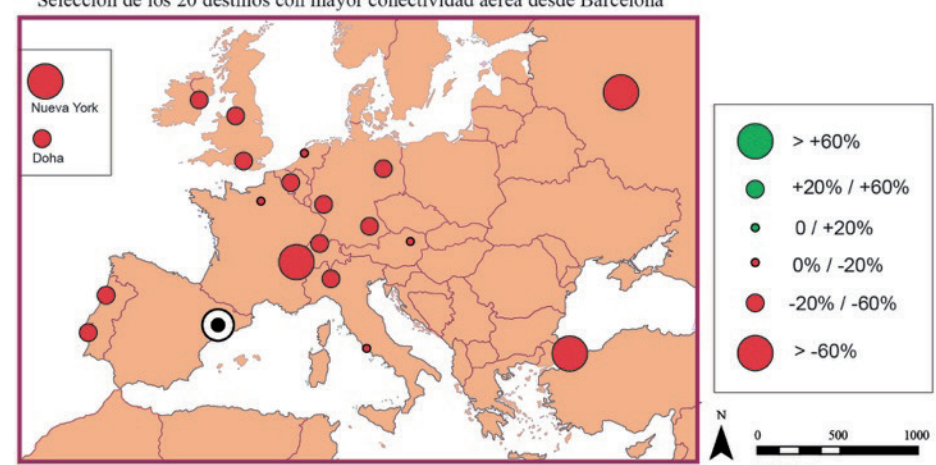

Figura 10. Tasa de variación de las frecuencias aéreas a los 20 principales destinos internacionales en los aeropuertos de Madrid (arriba) y Barcelona (abajo). Evolución 2015-2019 (izquierda) y 2019- 2020 (derecha). Fuente: Elaboración propia a partir de los resultados de la investigación; fuente primaria: Comber International Guides -OAG.

\section{DISCUSIÓN}

A continuación, se muestran algunas ideas que pretenden presentar una reflexión sobre los hechos descritos en estas páginas, pero especialmente, sobre las incógnitas que la pandemia ha abierto en relación con el sector de los viajes aéreos. En este sentido, el análisis realizado presenta los cambios para un periodo muy concreto, pero al tratarse de un proceso en marcha, todavía no pueden extraerse conclusiones generales sobre lo sucedido.

Se debe, en primer lugar, señalar algunas limitaciones del estudio. Principalmente, para el análisis de la evolución de la intensidad de las relaciones domésticas entre nodos sería muy interesante haber dispuesto de datos de tráfico de pasajeros entre pares de ciudades. Se ha contado con datos de conexiones y frecuencias, pero es cierto que a veces no reflejan en toda su complejidad la magnitud del cambio. Por otra parte, metodológicamente, en la elaboración de los coeficientes de conectividad ajustados (CCA) quizá deba revisarse el umbral de $250 \mathrm{~km}$ de competencia entre aeropuertos, fundamentalmente en lo que concierne a los vuelos domésticos. No obstante, se estima que los resultados utilizando umbrales algo inferiores tampoco divergirían excesivamente de los obtenidos.

En términos generales, se ha puesto de manifiesto que la trayectoria del sistema de transporte aéreo en España en el extenso periodo estudiado ha tenido como consecuencia la conformación de una red muy madura y vertebrada, con una trayectoria continuada desde hace casi medio siglo. Se aprecia también una concentración de la actividad en una decena de aeropuertos, en relación con las localizaciones turísticas y con los dos hub estatales, Barcelona y Madrid. En este contexto, la irrupción de la crisis sanitaria supuso, en un primer momento, una caída de la actividad sin precedentes, con un reinicio de las operaciones paulatino y donde, a fecha de hoy, todavía no se han alcanzado las cifras de partida. Las últimas noticias al respecto señalan, a escala mundial, una recuperación de la actividad aérea más rápida de lo esperado (Hosteltur, 2021), aunque para el caso de España es necesario disponer de datos que confirmen esta tendencia. También es una incógnita cómo se desarrollará en el medio-largo plazo la recuperación del sector de la aviación 
civil comercial en otros sistemas aéreos nacionales tras la pandemia y si habrá cambios irreversibles. Para el caso de Japón, Corea o China se ha mostrado que el sector de los vuelos domésticos se revitalizó antes que los vuelos internacionales ( $\mathrm{Ng}$ et al., 2021; Kim \& Sohn, 2022; Sun et al., 2021b). En consecuencia, se ha constatado que los viajes nacionales demostraron una mayor resistencia y dominaron los escenarios de recuperación del tráfico, particularmente en China y Rusia, donde el número de pasajeros nacionales a finales de 2020 ya había alcanzado cifras cercanas a los niveles previos a la pandemia (Aeroespacial, 2021). No obstante, debido a su prolongada duración y la incidencia de las diferentes olas es necesario disponer de una perspectiva temporal de amplio alcance.

Pero, la magnitud de las cifras trasciende la movilidad física de aeronaves y personas, al demostrarse la imbricación y la simbiosis del sistema de transporte con las dinámicas sociales y económicas y los posibles cambios o la generación de nuevas lógicas a la hora de decidir realizar un desplazamiento utilizando el avión. Las transformaciones son evidentes, por ejemplo, en el ámbito del teletrabajo y la necesidad a futuro de desplazamientos de ejecutivos y altos empleados de las empresas. Ello obliga a replantear en qué circunstancias será necesario un trayecto físico y la utilización de aeronaves (Comisión Europea, 2020). También es una incógnita en qué términos se restablecerá la actividad turística mundial. Un reciente informe de Amadeus (2021a), señala que el sector de los viajes se está reactivando en relación con las siguientes claves motivacionales: búsqueda de viajes a destinos o experiencias épicas (turismo experiencial), desplazamientos para visitar a amigos y familiares, opciones más sostenibles y responsables de turismo (ecoturismo y turismo solidario), la preferencia por destinos que han sido localizaciones de series y películas y por último, la reactivación de los viajes de negocios. Pese a estas predicciones, y en relación con el último caso, parece que no todos los modelos señalan la reactivación de los mismos en el largo plazo y así, algunos auguran que por causa de la pandemia se producirá una caída, con respecto a las previsiones iniciales, de entre un 14 y un 45\% (Mason, 2021). Por otra parte, diferentes modelos indican que en el futuro, una vez restablecida la movilidad a escala mundial, los principales aeropuertos (hubs globales) volverán a sufrir congestión y una crisis importante de capacidad (Gelhausen et al., 2021), con lo que podría haberse desperdiciado la oportunidad de incidir en la racionalidad y sostenibilidad del sector de los viajes aéreos.

Otras cuestiones que forman parte del debate actual están en relación con el futuro de las compañías y las medidas necesarias para favorecer la recuperación del sector desde el punto de vista de la activación de la demanda. El lamentable estado de cuentas en el que han quedado las aerolíneas, no solo las españolas, por efecto de la pandemia augura posibles quiebras o nuevas restructuraciones. Por ejemplo, la empresa propietaria de Iberia y Vueling, IAG, perdió 6.923 millones de euros a consecuencia de la crisis. También ha sido muy polémico el rescate por parte del Gobierno de España de la empresa Air Europa, por una cifra de 475 millones de euros (Cordero, 2021). Igualmente, ha tenido importante repercusión mediática la retirada de sus operaciones en Girona -lo que ha significado que este aeropuerto esté técnicamente sin actividad-y en los aeropuertos canarios (Lanzarote, Las Palmas de G.C., Tenerife) por parte de la compañía Ryanair. Este es un hecho que ya había anticipado esta aerolínea, pero que la crisis sanitaria ha acelerado (Rovira, 2020).

Así, resulta interesante el papel regulatorio, de restauración de la confianza y para garantizar las conectividades regionales que puede tener en el futuro la iniciativa política, ya que esta crisis ha hecho desaparecer algunas rutas regionales y también algunas aerolíneas (Xuan et al., 2021). Este aspecto ya ha sido puesto en valor, por ejemplo, en los casos de Japón ( $\mathrm{Ng}$ et al., 2021) o Corea del Sur (Kim \& Sohn, 2022). También es significativo cómo las ayudas recibidas por muchas compañías aéreas, fundamentales para la supervivencia del sector durante la primera ola de la pandemia por ejemplo en el caso europeo, pueden "cambiar las reglas de competencia entre empresas y las perspectivas de éxito en el futuro de las aerolíneas, porque si bien se proporciona recursos, también se limita el margen de maniobra para desarrollar estrategias, operaciones y las decisiones de gestión, como en la elección de rutas, la determinación de los hubs y los encargos de aviones y tecnología" (Albers \& Rundshagen, 2020 en Cifuentes \& Faura, 2021, p. 239).

Por otra parte, aunque las aerolíneas comerciales tradicionales han mostrado su vulnerabilidad a la crisis, se cuenta también con ejemplos en los que compañías han solventado el periodo con beneficios. Se trata de negocios dedicados al sector de vuelos privados o particulares para empresas, directivos o personas de alto 
poder adquisitivo (Cordero, 2021). El tipo de servicio que se ofrece resulta también muy conveniente para garantizar la recomendada "distancia social", evitando la masificación de aeropuertos y aeronaves.

En relación con esta idea, también el sector profesional del transporte aéreo incide en la recuperación de la confianza, garantizando vuelos seguros desde el punto de vista sanitario, renovando también el prestigio de las aerolíneas (Cifuentes \& Faura, 2021). Estas se han adaptado implementando medidas como las propuestas por la Universidad de Harvard, esto es: el sistema de ventilación y de renovación periódica del aire en las cabinas, el uso de mascarillas, la desinfección de los aviones, la monitorización de los pasajeros y la educación y concienciación. Además, el sector se ha adecuado a las nuevas necesidades, ofreciendo mayor flexibilidad en las reservas -cancelaciones, cambios de vuelo, reintegro del precio del pasaje- (Xuan et al., 2021), aumentando las experiencias con poco contacto (low-touch) tanto en aeropuertos como en hoteles, permitiendo a los viajeros realizar sus trámites en el aeropuerto de manera remota a través de sus teléfonos móviles (Amadeus, 2021 b), u ofreciendo servicios sanitarios de diagnóstico rápido en los aeropuertos (PCRs) para presentar en aquellos destinos que lo solicitan obligatoriamente (Hosteltur, 2021b).

En el caso concreto de España, otra variable que debe ser considerada en relación con el restablecimiento de la actividad aérea es que el tráfico aéreo doméstico experimenta una fuerte competencia con el transporte ferroviario de alta velocidad (AVE). Muchos de los enlaces aéreos peninsulares, especialmente aquellos de carácter radial, habían visto retroceder la demanda ya antes de la pandemia ante el desarrollo de esta modalidad de transporte, que adquiere gran competitividad en trayectos inferiores a los 600-700 kilómetros (Díez-Pisonero, 2016). Esta no debe ser entendida solo en términos de tiempo total de desplazamiento, sino también en relación con cuestiones de comodidad, disponibilidad de frecuencias y puntualidad del servicio (Jánez, 2015). A ello se suma la liberalización del sector ferroviario con la entrada de compañías competidoras de RENFE en el mercado (SNCF o Ilsa), añadiendo la variable tarifa o precio del billete en esta difícil ecuación, lo que augura un nuevo reto a la continuidad de la actividad de las compañías aéreas en las rutas peninsulares, y con ello la actividad en algunos aeropuertos menores (Cinco Días, 2020).

Es interesante también anotar que las cuestiones ambientales (eficiencia energética, resiliencia frente a situaciones climáticas adversas) están cobrando protagonismo en la elección del ferrocarril de alta velocidad frente al avión (Prusi \& Lonza, 2018). Para el caso de Europa la opción del tren como medio de transporte más sostenible y coherente con el Pacto Verde Europeo y con la Acción de la Unión Europea por el clima parece ser una iniciativa interesante (European Union- Agency for Raylways, 2020). No obstante, el ferrocarril de alta velocidad también presenta algunos inconvenientes que no pueden subestimarse, como la altísima inversión en el tendido de las rutas, los impactos en los paisajes y en los hábitat naturales, o el efecto túnel; aparte, se pueden estar subestimando los esfuerzos del sector de la construcción aeronáutica para diseñar aeronaves que reduzcan considerablemente las emisiones de $\mathrm{CO}_{2}$ (Eurocontrol, 2021), lo que proporcionará artefactos mucho más eficientes energéticamente y sostenibles en un futuro no muy lejano.

Conviene, por último, para el caso concreto de la red estatal de aeropuertos poner de manifiesto su disimetría y cuestionar la viabilidad de aquellos más modestos, lo que puede haberse agravado por el impacto de la pandemia. Es decir, es preciso conocer hasta qué punto la oferta actual de estas instalaciones es dependiente de las ayudas públicas y por cuánto tiempo las diferentes administraciones podrán mantenerlas. Del mismo modo, será necesario discutir sobre el modelo de gestión aeroportuaria. Frente al modelo público instaurado en la actualidad, donde la gestión de todos los aeropuertos públicos es implementada por AENA, la Unión Europea promueve otro modelo más descentralizado, cada vez más presente en países vecinos, donde exista una unidad gestora para cada infraestructura aeroportuaria (Directiva UE 96/67; Unión Europea, 1996).

\section{CONCLUSIONES}

La conectividad aérea española ha evolucionado significativamente durante los últimos 45 años, estudiados en estas líneas, consolidándose una red muy tupida y vertebrada. Así, frente a la estructura bicéfala de 1970, 
articulada por dos centros dominantes en un sistema manifiestamente concentrado, se ha evolucionado a otro donde, aunque Madrid y Barcelona siguen dominando las relaciones domésticas e internacionales, aparecen centralidades emergentes para la estructuración del territorio asociadas a la revalorización de núcleos regionales (Henneberg et al., 2007).

Respecto a la red internacional, aunque Madrid sigue teniendo el CC más elevado del país por su condición de hub (principal puerta de entrada y salida aérea), lo verdaderamente significativo es el crecimiento experimentado en un gran número de aeropuertos como consecuencia de la entrada de España en la Unión Europea, la gran especialización turística del país o la expansión de las compañías de bajo coste, entre otros factores.

Partiendo de esta trayectoria, el impacto de la COVID-19 sobre el transporte aéreo está suponiendo un verdadero punto de inflexión en la historia aeronáutica, independientemente de la escala de análisis y de las métricas tenidas en consideración. En España, las frecuencias y conexiones aéreas de todos sus aeropuertos se han visto mermadas durante los meses más duros del confinamiento, aunque es importante señalar que una operatividad suficiente de la red ya estaba restablecida en el verano de 2020.

Con este panorama, es fundamental aportar certidumbre en materia de salud y seguridad para la reconstrucción de la confianza de los usuarios. Algunas medidas, ya citadas, se han llevado a efecto en la mayor parte de los aeropuertos del mundo, como la desinfección de terminales, el uso de mascarillas, guantes y geles sanitarios, el control del aforo de tiendas y restaurantes, el distanciamiento social, etc. Una prueba de que las compañías aéreas y los aeropuertos ya están aplicando con éxito estos protocolos es que el riesgo de transmisión a bordo es bajo (Wyman, 2020).

Pero, en vista del temor a constantes rebrotes y olas en todo el mundo y la mutabilidad del virus de la COVID-19, no es posible predecir con exactitud cuándo se levantarán la totalidad de las restricciones a los desplazamientos, cuándo se volverá a una situación "de normalidad" o prepandémica o si algunas transformaciones serán irreversibles. A estos retos, enfocados en garantizar certidumbre en salud y seguridad, debe añadirse la consideración de la función de servicio público que también tiene el sector de la aviación, en muchos casos subestimada. El retroceso experimentado desde la primavera de 2020 justifica la necesidad de velar por la sostenibilidad en un sector indispensable para garantizar la interacción económica y social.

\section{Agradecimientos}

Los autores quieren expresar su reconocimiento y agradecer a los/as revisores/as el esmero en la revisión del manuscrito y sus valiosas y constructivas recomendaciones.

\section{Declaración responsable y conflicto de intereses}

Los autores/as declaran que no existe ningún conflicto de interés en relación con la publicación de este artículo. Todas las tareas realizadas (obtención de fuentes, tratamiento de la información, elaboración del marco teórico, obtención e interpretación de resultados, redacción de los apartados, elaboración del material gráfico y cartográfico) en el manuscrito se han repartido al 50\% entre ambos autores. El diseño metodológico ha recaído en el Dr. Díez-Pisonero.

\section{REFERENCIAS}

ABC World Airways Guide (1970). Thos Skiner and Co. October 1970. London. World flights database (all flights, to/from all airports worldwide).

ABC World Airways Guide (2015). Digital Comber International Guides -OAG (all flights, to/from all airports worldwide; november). 
ABC World Airways Guide (2020). Digital Comber International Guides -OAG (all flights, to/from all airports worldwide; august). AENA (2015, 2019, 2020, 2021). AENA Estadísticas. Pasajeros, Operaciones y Carga. AENA. http://www.aena.es/csee/Satellite?pagename=Estadisticas/Home

Aeroespacial (2021). El tráfico internacional de pasajeros cae un 60\% en 2020, según la OACI. Aeroespacial. https://actualidadaeroespacial.com/el-trafico-internacional-de-pasajeros-cae-un-60-en-2020-segun-la-oaci/

Agnew, J. (2001). The new global economy: time-space compression, geopolitics, and global uneven development. Journal of world-systems research, VII,2, 133-154. https://doi.org/10.5195/jwsr.2001.16.

Albers, S. \& Rundshagen, V. (2020). European airlines' strategic responses to the COVID-19 pandemic (January-May, 2020). Journal of air transport management, 87, 101863. https://doi.org/10.1016/j.jairtraman.2020.101863.

Amadeus (2021a). Seis tendencias que revitalizarán el espacio de los viajes en 2022. In: Amadeus. https://amadeus.com/ es/articulos/blog/seis-tendencias-que-revitalizaran-el-espacio-de-los-viajes-en-2022

Amadeus (2021b). COVID-19. Impacto y respuesta de Amadeus. In: Amadeus, Informe Global Amadeus 2020. https://corporate.amadeus.com/documents/es/recursos/informacion-empresarial/documentos-corporativos/informes-globales/2020/covid-19-impacto-y-respuesta-amadeus.pdf

Antón, F.J. \& Córdoba, J. (1999). La liberalización del transporte aéreo en España. Boletín de la Asociación de Geógrafos Españoles, 19, 113-132.

Atlas Magazine (2020). Impact of Covid-19 on the aviation sector. Report. https://www.atlas-mag.net/en/article/impactof-covid-19-on-the-aviation-sector

Bel, G. \& Fageda, X. (2006). Aeropuertos y Globalización: Opciones de gestión aeroportuaria e implicaciones sobre el territorio. IERMB. Universidad Autónoma de Barcelona.

Cano, G. (1980). El transporte aéreo en España. Ariel.

Cifuentes-Faura, J. \& Faura-Martínez, U. (2021). Situation of European airlines caused by COVID-19: restrictions, government subsidies and future prospects. Aviation, 25(4), 232-240. https://doi.org/10.3846/aviation.2021.15882.

Cinco Días (2020). La liberalización ferroviaria, un motor para la economía y la nueva movilidad. Cinco Días. https://cincodias.elpais.com/cincodias/2020/12/23/companias/1608755148_754350.html

Cinco Días (2021). La normativa europea de 'slots' mete presión sobre el futuro de Air Europa. Cinco Días. https://cincodias.elpais.com/cincodias/2021/11/05/companias/1636139071_872193.html

Chi, J. \& Baek, J. (2013). Dynamic relationship between air transport demand and economic growth in the United States: A new look. Transport Policy, 29, 257-260. https://doi.org/10.1016/j.tranpol.2013.03.005

Comisión Europea (2020). Telework in the EU before and after the COVID-19: where we were, where we head to. European Commission. https://ec.europa.eu/jrc/sites/jrcsh/files/jrc120945_policy_brief___covid_and_telework_final.pdf

Cordero, D. (2021). Gestair: la aerolínea española que capeó el temporal de la pandemia. El País. https://elpais.com/economia/2021-09-21/gestair-la-aerolinea-espanola-que-capeo-el-temporal-de-la-pandemia.html

Córdoba, J., Gago, C. \& Serrano, M. (2007). Transporte aéreo y espacialidad diferencial. En S. Gutiérrez \& J. Sanz (Eds.), Homenaje al Profesor J.M. Casas Torres (pp. 45- 64). Universidad Complutense.

Córdoba, J. \& Gago, C. (2010). Latin American cities and globalisation: change and permanency in the context of development expectations. Urban Studies, 47(9), 2003-2021. https://doi.org/10.1177/0042098010372680

Cumings, B. (1999). Still the American century. Review of International Studies, 25, 271-299. https://doi.org/10.1017/ S0260210599002715

Díez-Pisonero, R. (2016). El aeropuerto y la ciudad en los escenarios de la globalización: una simbiosis necesaria y cambiante (Tesis doctoral). Universidad Complutense, Madrid.

Dobruszkes, F. \& Van Hamme, G. (2011). The impact of the current economic crisis on the geography of air traffic volumes: an empirical analysis. Journal of transport geography, 19(6), 1387-1398. https://doi.org/10.1016/j.jtrangeo.2011.07.015.

Eurocontrol (2021). Plane and train: Getting the balance right. Aviation Sustainability Unit. Think Paper 11, 3 June 2021. https://www.eurocontrol.int/sites/default/files/2021-06/eurocontrol-think-paper-11-plane-and-train-right-balance.pdf

European Union- Agency for Raylways (2020). Report: Fostering the railway sector through the European Green Deal. ERA1234. https://www.era.europa.eu/sites/default/files/events-news/docs/fostering_railway_sector_through_european_green_deal_en.pdf 
Exceltur (2020). Impacto de la COVID-19 sobre el sector turístico español. Perspectivas Turísticas, nº 73, junio. https://www. exceltur. org/wp-content/uploads/2020/10/Informe-Perspectivas-N73-Balance-empresarial-y-escenario-impacto-Covid-19.pdf

Forer, P. (1978). A place for plastic space. Progress Human Geography, 2, $230-267$. https://doi. org/10.1177/030913257800200203

Gago, C. (2003). Región, Política y Transporte aéreo (Tesis doctoral). Universidad Complutense, Madrid.

Gámir, A. \& Ramos, D. (2011). Los pequeños aeropuertos regionales de la España peninsular: dinámicas recientes y perspectivas de futuro. Ería, 77- 102.

Gelhausen, M.C., Berster, P, \& Wilken, D. (2021). Post-COVID-19 Scenarios of Global Airline Traffic until 2040 That Reflect Airport Capacity Constraints and Mitigation Strategies. Aerospace, 8(10), 300. https://doi.org/10.3390/aerospace8100300

Graham, B. (1995). Geography and air transport. Wiley.

Harvey, D. (1983). Teorías, leyes y modelos en geografía. Alianza.

Henneberg, J.M., Tapiador, F.J. \& Campos, A. (2007). La eclosión de los aeropuertos regionales españoles. Universidad de Castilla-La Mancha, Lleida y Zaragoza. Fundación Abertis.

Hernández Luis, J.Á. (2010). El transporte aéreo interinsular como factor de cohesión territorial en las Islas Canarias. Revista Transporte y Territorio, 2, 38-67. https://doi.org/10.34096/rtt.i2.233

Hosteltur (2021a). El transporte aéreo se recupera de la pandemia más rápido de lo esperado. Hosteltur. https://www. hosteltur.com/lat/147511_el-transporte-aereo-se-recupera-de-la-pandemia-mas-rapido-de-lo-esperado.html

Hosteltur (2021b). La seguridad sanitaria, principal prioridad para Vueling. Hosteltur. https://www.hosteltur.com/142334_ la-seguridad-sanitaria-principal-prioridad-para-vueling.html

IATA (2020). El impacto del Covid-19 en la aviación europea. IATA. https://www.vadeaviones.com/2020/08/13/el-impactodel-covid-19-en-la-aviacion-europea/

IATA (2021). Key to Air Cargo Resilience Post Pandemic: Cooperation, Safety, Sustainability, Modernization. IATA. https://www. iata.org/en/pressroom/2021-releases/2021-10-12-01/

Inglada, V. \& Rey, B. (2004). Spanish air travel and the September 11 terrorist attacks: a note. Journal of Air Transport Management, 10, 441-443. https://doi.org/10.1016/j.jairtraman.2004.06.002

Ito, H. \& Lee, D. (2005). Assessing the impact of the September 11 terrorist attacks on U.S. airline demand. Journal of Economics and Business, 58, 75-95. https://doi.org/10.1016/j.jeconbus.2004.06.003

Ishutkina, M. \& Hansman, R.J. (2008). Analysis of Interaction between Air Transportation and Economic Activity. The 26th Congress of ICAS and 8th AIAA ATIO (p. 8888). https://doi.org/10.2514/6.2008-8888

Janelle, D.J. (1969). Spatial reorganization: A model and concept. Annals of the Association of American Geographers, 59, 348-364. https://doi.org/10.1111/j.1467-8306.1969.tb00675.x

Jánez, J.F. (2015). Una visión actualizada de la competencia entre el tren de alta velocidad y el avión. Revista de Alta Velocidad, 3, Octubre, 19-32.

Kim, M. \& Sohn, J. (2022). Passenger, airline, and policy responses to the COVID-19 crisis: The case of South Korea. Journal of air transport management, 98, 102144. https://doi.org/10.1016/j.jairtraman.2021.102144

Knowles, R. (2006). Transport shaping space: differential collapse of time-space. Journal of Transport Geography, 14, 407425. https://doi.org/10.1016/j.jtrangeo.2006.07.001.

Larsen, J., Urry, J. \& Auxhausen, K. (2006). Mobilities, networks, geographies. Ashgate. https://doi. org/10.1080/17450100600726654

Mason, K.J. (2021). Corona Markiert Eine Zäsur bei Geschäftsreisen. Airlines.de. 23- 08-2021. https://www.airliners.de/ airlinegeschaeftsmodelle-88-corona-markiert-zaesur-geschaeftsreisen/61658

Muñoz, R. (2021). AENA duplica pérdidas en el primer semestre hasta los 346,4 millones. El País, 28- 07- 2021. https:// elpais.com/economia/2021-07-28/aena-duplica-perdidas-en-el-primer-semestre-hasta-los-3464-millones.html

Ng, K.T., Fu, X., Hanaoka, S. \& Oum, T.H. (2022). Japanese aviation market performance during the COVID-19 pandemic-Analyzing airline yield and competition in the domestic market. Transport Policy, 116 (2022) 237-247. https:// doi.org/10.1016/j.tranpol.2021.12.006

OACI (2020). ICAO Report on the Effects of COVID-19 on Civil Aviation, 17 December 2020. ICAO. https://www.icao.int/sustainability/Documents/COVID-19/ICAO\%20COVID\%202020\%2012\%2017\%20Economic\%20Impact.pdf 
OACI (2021a). Effects of Novel Coronavirus (COVID-19) on Civil Aviation: Economic Impact Analysis, 17 September 2021. ICAO. https://www.icao.int/sustainability/Documents/COVID-19/ICAO\%20COVID\%202021\%2009\%2007\%20Economic\%20Impact\%20TH\%20Toru.pdf

OACI (2021b). Air Cargo. Priority brief. ICAO. https://www.icao.int/sustainability/Documents/ICAO-PRIORITY-BRIEF_ Air-Cargo_2021.04.19.FINAL.pdf

OACI (2021c). El volumen total de pasajeros en 2020 se redujo un 60 \% y el asalto de la COVID-19 a la movilidad internacional no se detiene. ICAO. https://www.icao.int/Newsroom/Pages/ES/2020-passenger-totals-drop-60-percent-as-COVID19-assault-on-international-mobility-continues.aspx

OECD (2021). OECD Economic Outlook, Volume 2021 Issue 2: Preliminary version. OECD. https://doi.org/10.1787/66c5ac2c-en Omic, J. \& Van Mieghem, P. (2010). Pandemics and networks: the case of the Mexican flu. World Congres on Engineering \& Computer Science (WCECS 10), 20-22 October 2010, San Francisco, USA.

Oprea, M. (2010). The effects of global economic crisis on the air transport of passengers in Europe and in Romania. GeoJournal of Tourism and Geosites, 5(1), 52-61.

Prussi, M. \& Lonza, L. (2018). Passenger aviation and high speed rail: a comparison of emissions profiles on selected European routes. Journal of Advanced Transportation, 2018. https://doi.org/10.1155/2018/6205714

Relp, E. (1976). Place and Placelessness. Londres: Pion.

Ribeiro, S.P., Silva, A.C., Dáttilo, W., Reis, A.B., Góes-Neto, A., Alcantara, L.C J. \& Azevedo, V.A.C. (2020). Severe airport sanitarian control could slow down the spreading of COVID-19 pandemics in Brazil. PeerJ, 8, e9446. https://doi. org/10.7717/peerj.9446

Rovira, M. (2020). La salida de Ryanair del aeropuerto de Girona deja en el aire 100 empleos. El País. https://elpais.com/espana/catalunya/2020-11-08/la-salida-de-ryanair-del-aeropuerto-de-girona-deja-en-el-aire-100-empleos.html

Serrano, J.M. (1999). Tráfico aéreo de pasajeros, turismo y red aeroportuaria en España a finales del siglo XX. Algunas consideraciones. Cuadernos de Turismo, 4, 73-88.

Serrano, J.M. \& García, R. (2015). Local low-traffic airports in Spain: problems and the necessary reorganisation of the territorial network. Boletín de la Asociación de Geógrafos Españoles, 67, 251-274.

Stein, J. (2001). Reflections on time, time-space compression and technology in the nineteenth century. In: J. May \& N. Thrift. Timespace: Geographies of Temporality (106-119). Routledge.

Sun, X., Wandelt, S., Zheng, C. \& Zhang, A. (2021a). COVID-19 pandemic and air transportation: Successfully navigating the paper hurricane. Journal of Air Transport Management, 102062. https://doi.org/10.1016/j.jairtraman.2021.102062

Sun, X., Wandelt, S., Fricke, H., \& Rosenow, J. (2021b). The Impact of COVID-19 on Air Transportation Network in the United States, Europe and China. Sustainability, 13(17), 9656. https://doi.org/10.3390/su13179656

Sorupia, E. (2005). Rethinking the role of transportation in tourism. In Proceedings of the Eastern Asia Society for Transportation Studies, 5, 1767-1777.

Unión Europea (1996). Directiva 96/67/CE del Consejo de 15 de octubre de 1996 relativa al acceso al mercado de asistencia en tierra en los aeropuertos de la Comunidad. Unión Europea. https://op.europa.eu/en/publication-detail/-/ publication/14ae9263-70dd-479a-9f5c-c1a1f40c148f/language-es/format-PDFA1B

Urry, J. (2000). Sociology Beyond Societies: Mobilities for the Twenty-first Century. Routledge.

Villarroya, J.M., Maudos, J., Monsálvez, J.M.P., Pastor, J.M. \& Martínez, L.S. (2006). Productividad e internacionalización: el crecimiento español ante los nuevos cambios estructurales. Fundación BBVA.

Vizcaíno, M.L. (2015). Evolución del turismo en España: el turismo cultural. International journal of scientific management and tourism, 1(4), 75-95.

Wensveen, J.G. \& Leick, R. (2009). The long-haul low-cost carrier: A unique business model. Journal of Air Transport Management, 15(3), 127-133. https://doi.org/10.1016/j.jairtraman.2008.11.012

Wyman, O. (2020). El impacto inmediato del coronavirus en el transporte aéreo será peor que el del 11S. Cotizalia Empresas. https:// www.elconfidencial.com/empresas/2020-05-25/impacto-inmediato-coronavirus-transporte-aereo-peor-11s_2609296/

Xuan, X., Khan, K., Su, C.W. \& Khurshid, A. (2021). Will COVID-19 Threaten the Survival of the Airline Industry? Sustainability, 13(21), 11666. https://doi.org/10.3390/su132111666 